GUSTAVO TIAEN

Estudo retrospectivo das radiografias de necrose asséptica da cabeça femoral em cães

São Paulo

2012 


\title{
GUSTAVO TIAEN
}

\section{Estudo retrospectivo das radiografias de necrose asséptica da cabeça femoral em cães}

\begin{abstract}
Dissertação apresentada ao Programa de Pós-Graduação em Clínica Cirúrgica Veterinária da Faculdade de Medicina Veterinária e Zootecnia da Universidade de São Paulo para obtenção do título de Mestre em Ciências
\end{abstract}

Departamento:

Cirurgia

Área de concentração:

Clínica Cirúrgica Veterinária

Orientador:

Prof. Dr. Stefano Carlo Filippo Hagen

São Paulo

2012 
Autorizo a reprodução parcial ou total desta obra, para fins acadêmicos, desde que citada a fonte.

DADOS INTERNACIONAIS DE CATALOGAÇÃO-NA-PUBLICAÇÃO

(Biblioteca Virginie Buff D’Ápice da Faculdade de Medicina Veterinária e Zootecnia da Universidade de São Paulo)

Tiaen, Gustavo

Estudo retrospectivo das radiografias de necrose asséptica da cabeça femoral em cães / Gustavo Tiaen. -- 2012.

76 f., il.

Dissertação (Mestrado) - Universidade de São Paulo. Faculdade de Medicina Veterinária e Zootecnia. Departamento de Cirurgia, São Paulo, 2012.

Programa de Pós-Graduação: Clínica Cirúrgica Veterinária.

Área de concentração: Clínica Cirúrgica Veterinária

Orientador: Prof. Dr. Stefano Carlo Filippo Hagen.

1. Necrose asséptica da cabeça femoral. 2. Cães. 3. Radiografia. 4. Classificação. I. Título. 


\section{FACULDADE DE MEDICINA VETERINÁRIA E ZOOTECNIA}

\section{Comissão de Ética no uso de animais}

\section{CERTIFICADO}

Certificamos que o Projeto intitulado "Estudo retrospectivo das radiografias de necrose asséptica da cabeça femoral em cães", protocolado sob o n“2îư j 2010 , não utilizando animais, sob a responsabilidade do Prof. Dr. Franklin de Almeida Sterman, está de acordo com os princípios éticos de experimentação animal da "Comissão de Ética no uso de animais" da Faculdade de Medicina Veterinária e Zootecnia da Universidade de São Paulo e foi aprovado em reunião de $16 / 03 / 2011$.

We certify that the Research "Retrospective study of the radiographs of aseptic necrosis of the femoral head in dogs", protocol number 2107/2010, under the responsibility Prof. Dr. Franklin de Almeida Sterman, agree with Ethical Principles in Animal Research adopted by "Ethic Committee in the use of animals" of the School of Veterinary Medicine and Animal Science of University of São Paulo and was approved in the meeting of day 03/16/2011.

São Paulo, 18 de março de 2011

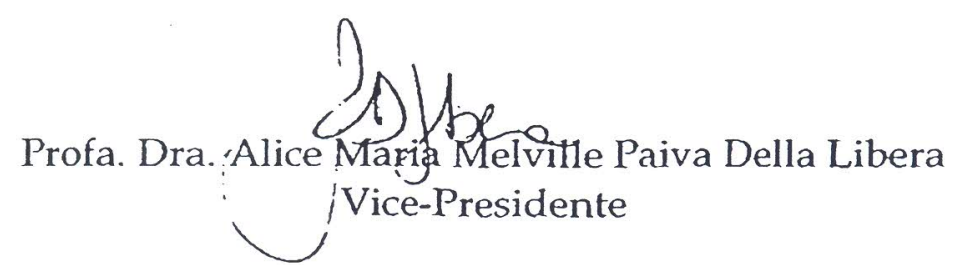


FOLHA DE AVALIAÇÃO

Nome do autor: TIAEN, Gustavo

Título: Estudo retrospectivo das radiografias de necrose asséptica da cabeça femoral em cães

Dissertação apresentada ao Programa de Pós-Graduação em Clínica Cirúrgica da Faculdade de Medicina Veterinária e Zootecnia da Universidade de São Paulo para obtenção do título de Mestre em Medicina Veterinária

Data: 1

Banca Examinadora

Prof. Dr.

Instituição: Julgamento:

Prof. Dr.

Instituição: Julgamento:

Prof. Dr.

Instituição: Julgamento: 
Dedico os resultados e as conclusões contidas nessa dissertação ao Prof. Dr. Franklin de Almeida Sterman (in memorian). 


\section{AGRADECIMENTOS}

Agradeço o Prof. Dr. Franklin de Almeida Sterman (in memorian) por ter acreditado em mim e ter me aceitado no programa de pós-graduação da Faculdade de Medicina Veterinária e Zootecnia da Universidade de São Paulo (FMVZ-USP) e pela sugestão do tema deste trabalho.

Ao Prof. Dr. Stefano Carlo Filippo Hagen que aceitou e me orientou neste trabalho, mostrando diversas linhas de raciocínio e pensamento que eu jamais teria conseguido seguir sem suas valiosas sugestões. Agradeço imensamente por sua ajuda, paciência e bom humor na confecção dessa dissertação. E por todo o aprendizado desta etapa da minha vida.

À Prof. a Sandra Maria de Oliveira que me apresentou ao Prof. Dr. Franklin de Almeida Sterman e acreditou no meu potencial. Uma pessoa que tenho verdadeira admiração por seu conhecimento como profissional e carinho como pessoa.

À minha esposa, Camila da Cruz Lopes Tiaen, pela paciência, pelo amor e apoio em todos os momentos da minha vida. Aos meus pais, Sérgio Yoshiaki Tiaen e Lúcia Morilhara, e irmã, Mariana Tiaen, pela força e conselhos. Aos meus sogros Luiz Felipeti Lopes e Maria Fátima da Cruz Lopes.

À Rejane Figueiredo pela orientação estatística.

Aos amigos Paulo Frazão e Denise Gonçalves pelas correções e observações realizadas neste trabalho.

À Prof. ${ }^{a}$ Ana Carolina Brandão de Campos Fonseca Pinto e Prof. ${ }^{a}$ Carla Aparecida Batista Lorigados. As médicas veterinárias Luciane M. Kanawama e Silvana Unruh. Aos pós-graduandos do departamento de Diagnóstico por Imagem da FMVZ-USP, Carolina de Oliveira Ghirelli, Luciana Fortunato Burgese Lanza, Carina Outi Baroni, Gabriela Paola Ribeiro Banon, Thelma Cintra Silva e Lenin Arturo Villamizar Martinez, pelo companheirismo, ajuda e orientações.

Aos amigos Maurício Zago Flocke, Rafael Magdanelo Leandro, Igor Alexandre Quirico, Gabriel Cocchi de Bellis, Daniel dos Santos Baptista, Maria Madalena Rosa de Carvalho.

Todos os professores, médicos veterinários, residentes, estagiários, alunos e funcionários do Hospital Veterinário da Universidade de Santo Amaro (UNISA) e do Hospital Veterinário da Faculdade de Medicina Veterinária da Universidade de São Paulo (FMVZ-USP). 


\section{RESUMO}

TIAEN, G. Estudo retrospectivo das radiografias de necrose asséptica da cabeça femoral em cães. [Retrospective study of radiographs of aseptic necrosis of the femoral head in dogs]. 2012. 76 f. Dissertação (Mestrado em Ciências) Faculdade de Medicina Veterinária e Zootecnia, Universidade de São Paulo, São Paulo, 2012.

A necrose asséptica da cabeça do fêmur (NACF) em cães é uma doença auto limitante do quadril em desenvolvimento, caracterizada por uma necrose asséptica, seguida por fratura subcondral, fragmentação, revascularização e remodelação na cabeça femoral. A etiologia da doença é obscura. A radiografia é a modalidade de imagem padrão utilizada para diagnosticar a doença em cães. Foi realizado um estudo retrospectivo de janeiro de 2000 até janeiro de 2010 nas radiografias de coxal com NACF nos cães atendidos no Hospital Veterinário da Faculdade de Medicina Veterinária e Zootecnia da Universidade de São Paulo. Radiografias com NACF foram reavaliadas e os graus de alterações radiográficas foram correlacionados a raça, sexo, idade, membro(s) acometido(s). Foi estudado também a evolução radiográfica dos pacientes que tinham mais de um exame realizado. Analisando os resultados, observou-se que as três principais raças acometidas foram Poodles, Yorkshires e Pinschers. A NACF acomete principalmente animais jovens e de pequeno porte, porém no estudo houve um animal de grande porte e alguns animais com idade avançada. Não houve uma predisposição sexual. Com relação aos membros acometidos, notou-se que o grau 5 da doença apresenta maior incidência no membro pélvico direito e ao estudar a evolução da NACF, observou-se tratar de uma doença progressiva e de evolução lenta. Foram avaliadas imagens em filme radiográfico e imagens digitalizadas, sendo possível fazer uma comparação entre os dois métodos. Todas as imagens digitalizadas foram encontradas, ao contrário das imagens em filme radiográfico, demonstrando a facilidade e rapidez que a digitalização pode trazer.

Palavras-chave: Necrose asséptica da cabeça femoral. Cães. Radiografia. Classificação 


\begin{abstract}
TIAEN, G. Retrospective study of radiographs of aseptic necrosis of the femoral head in dogs. [Estudo retrospectivo das radiografias de necrose asséptica da cabeça femoral em cães]. 2012. 76 f. Dissertação (Mestrado em Ciências) Faculdade de Medicina Veterinária e Zootecnia, Universidade de São Paulo, São Paulo, 2012.
\end{abstract}

Aseptic necrosis of the femoral head (ANFH) in dogs is a self limiting disease of the developing hip, characterized by an aseptic necrosis, followed by subchondral fracture, fragmentation, revascularization and remodeling of the femoral head. The etiology of the disease is unclear. In dogs the standard imaging modality is radiography. A retrospective study from January 2000 to January 2010 of ANFH cases attended at the Veterinary Hospital of the University of Sao Paulo was done. Radiographs of the hips diagnosed with ANFH where reexamined, the degree of changes established correlating data with breed, gender, age, and affected member. The three major breeds involved were Poodles, Yorkshires and Pinschers. The ANFH mainly affects young and small animals, but in this study there was one large animal and some animals with advanced age. There was no sexual predisposition. In the affected limbs, it was noted that the grade 5 of the disease has a higher incidence in the right limb. In patients with more than one examination evolution of the radiographic changes was analyzed. No regression of radiographic changes was registered and ANFH showed to be a progressive disease with slow evolution. To work with conventional and digital images showed no difficulty in reading but a substantial portion of conventional images were not found.

Keywords: Aseptic necrosis of the femoral head. Dogs. Radiographs. Classification 



\section{LISTA DE QUADROS}

Quadro 1 - Vantagens e desvantagens das diversas modalidades de imagem que podem ser utilizadas na NACF - São Paulo - 2012.

Quadro 2 - Descrição da classificação radiográfica das lesões da coxofemoral acometida pela doença de LCP - Copenhagen - 1967

Quadro 3 - Dados dos pacientes (identificação, raça, sexo, idade, data do estudo ou tempo de evolução da doença, membro(s) acometido(s) e grau da doença classificada radiograficamente), que foram encaminhados para o estudo estatístico - São Paulo - 2012 


\section{LISTA DE TABELAS}

Tabela 1 - Freqüências absolutas (n) e relativas (\%) relacionadas ás raças dos animais estudados, São Paulo - jan.-2000 / dez.-2010.

Tabela 2 - Grau da doença nas diversas raças, São Paulo - jan.-2000 / dez.2010.

Tabela 3 - Comparações entre as raças (Pinscher, Poodle, Yorkshire e Outros) e os graus da doença, São Paulo - jan.-2000 / dez.-2010 .

Tabela 4 - Frequências absolutas (n) e relativas (\%) relacionadas ao sexo dos animais, São Paulo - jan.-2000 / dez.-2010

Tabela 5 - Distribuição dos graus da doença e o sexo dos animais, São Paulo jan.-2000 / dez.-2010

Tabela 6 - Frequências absolutas (n) e relativas (\%) relacionadas ao(s) membro(s) acometido(s), São Paulo - jan.-2000 / dez.-2010 ................57

Tabela 7 - Tabela representando o resultado do teste Kappa, utilizado para avaliar a concordância entre os graus da doença nos dois membros acometidos do mesmo animal, São Paulo - jan.-2000 / dez.-2010 .

Tabela 8 Frequências absolutas (n) e relativas (\%) dos membros acometidos, São Paulo - jan.-2000 / dez.-2010

Tabela 9 - Distribuição dos graus da doença e o membro acometido dos animais, São Paulo - jan.-2000 / dez.-2010 ……………............................. 58

Tabela 10 - Variáveis quantitativas dos animais estudados, São Paulo - jan.2000 / dez.-2010

Tabela 11- Distribuição dos graus da doença e a idade dos animais, São Paulo jan.-2000 / dez.-2010

Tabela 12 - Comparação das variáveis relacionadas à idade (em meses) e os graus da doença, São Paulo - jan.-2000 / dez.-2010 


\section{LISTA DE FIGURAS}

Figura 1 - Primeiros autores que descreveram a doença, Arthur Legg (Estados Unidos), Jacques Calvé (França) e Georg Perthes (Alemanha)

Figura 2 - Waldenström (Suécia), autor que descreveu as características radiográficas desta doença, porém atribuindo-as à tuberculose.

Figura 3 - Trajetos extra-articulares e intra-articulares da artéria femoral circunflexa medial e suas ramificações. E a principal distribuição das artérias retinaculares inferiores

Figura 4 - Ramo principal da artéria circunflexa lateral do fêmur irrigando a porção posterior do colo femoral, trocanter maior e fossa trocantérica. E diversos ramos da artéria femoral circunflexa lateral penetrando na cápsula articular e ascendendo como artérias retinaculares superiores ..28

Figura 5 - Dissecação da musculatura para expor os vasos retinaculares inferiores. $E$ o trajeto dos vasos retinaculares inferiores descendendo da cápsula articular e se inserindo na artéria circunflexa medial.

Figura 6 - Radiografia das articulações coxofemorais em projeção ventrodorsal, ilustrando áreas líticas associadas à irregularidade da cabeça femoral direita, causando incongruência articular ....

Figura 7 - Imagens radiográficas ilustrando os graus da NACF segundo LJUNGGREN (1967). A. Grau 1: contorno de cabeça e colo femorais normais, com aumento da interlinha radiográfica e áreas radiotransparentes na cabeça femoral esquerda e, mais raramente, no colo femoral. Acetábulo sem alterações. B. Grau 2: nítido achatamento da cabeça femoral direita, sem aumento do espaço articular. Focos radiotransparentes mais numerosos e amplos na cabeça e colo femorais. Presença de pequeno osteófito na porção craniolateral da borda acetabular. C. Grau 3: alterações de contorno mais acentuadas, dificuldade em visualizar a cabeça femoral direita devido a irregularidade na superfície articular. Osteófito acetabular mais evidente. D. Grau 4: contorno normal da cabeça femoral está completamente perdido, podendo haver fragmentações. Somente algumas áreas apresentam densidade normal. E. Grau 5: grande fragmentação da cabeça femoral e acentuadas alterações morfológicas acetabulares do lado direito.

Figura 8 - Imagem radiográfica de NACF em um cão de porte grande, da raça Pastor Alemão. Observam-se proliferações ósseas periarticulares exuberantes em cabeça, colo e acetábulo direitos, que alteravam a morfologia da cabeça femoral e áreas líticas em permeio à cabeça femoral que poderia sugerir NACF 


\section{LISTA DE GRÁFICOS}

Gráfico 1 - Número total de imagens relacionadas à NACF e o número de imagens encontradas para o estudo, São Paulo - jan.-2000 / dez.-2010

Gráfico 2 - Porcentagem das imagens convencionais e digitalizadas em sua totalidade e a porcentagem encontrada, São Paulo - jan.-2000 / dez.2010

Gráfico 3 - Total de exames relacionados à NACF e o número de imagens encontradas a cada ano, São Paulo - jan.-2000 / dez.-2010 ..................59

Gráfico 4 - Frequência absoluta (n) e os graus da doença, São Paulo - jan.-2000 /

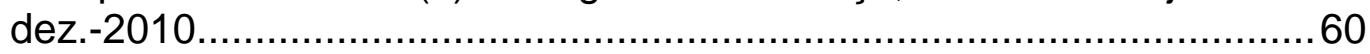

Gráfico 5 - Evolução dos graus iniciais e posteriormente os graus finais dos membros avaliados, São Paulo - jan.-2000 / dez.-2010 61

Gráfico 6 - Evolução dos graus da doença, São Paulo - jan.-2000 / dez.-2010 61 


\section{LISTA DE ABREVIATURAS E SIGLAS}

\begin{tabular}{ll} 
Dach. & Dachshound \\
Dez. & Dezembro \\
FMVZ-USP & Faculdade de Medicina Veterinária da Universidade de \\
& São Paulo \\
Fox P. & Fox Paulistinha \\
Fox T. & Fox Terrier \\
HOVET & Hospital veterinário \\
Jan. & Janeiro \\
LCP & Legg-Calvé-Perthes \\
Lhasa & Lhasa Apso \\
NACF & Necrose asséptica da cabeça femoral \\
P.A. & Pastor Alemão \\
RM & Ressonância magnética \\
Schn. & Schnauzer \\
SRD & Sem raça definida \\
TC & Tomografia computadorizada \\
\hline
\end{tabular}




\section{LISTA DE SÍMBOLOS}

$\% \quad$ Porcentagem

$<\quad$ Menor 


\section{SUMÁRIO}

1 INTRODUÇÃO

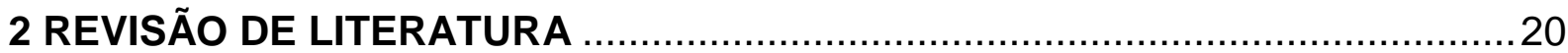

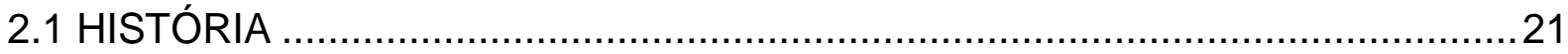

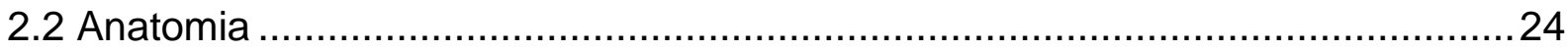

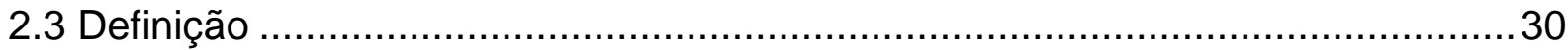

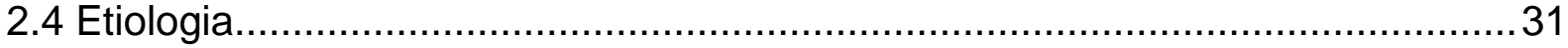

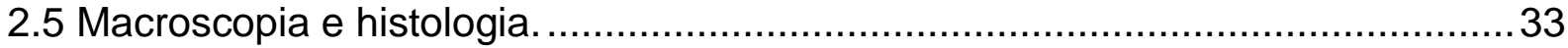

2.6 Epidemiologia

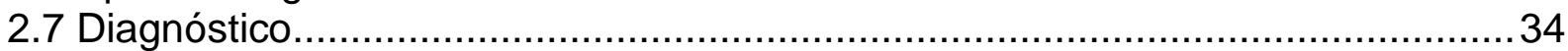

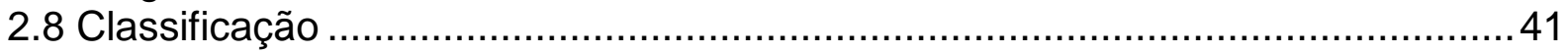

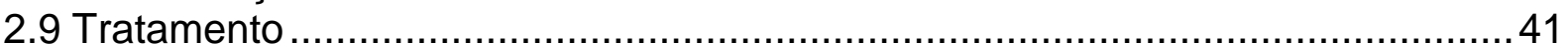

3 MATERIAL E MÉTODO

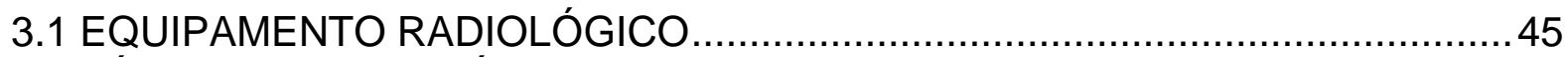

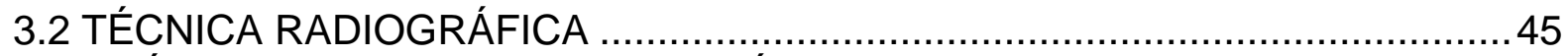

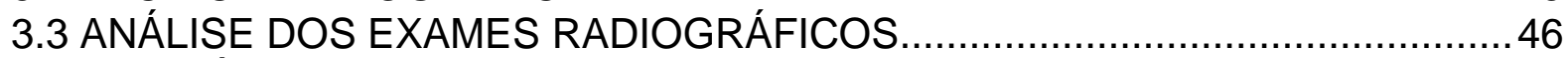

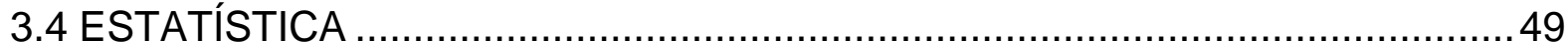

3.4.1 Estatística descritiva.................................................................................... 49

3.4.2 Comparação do grau da doença entre os diferentes membros de um

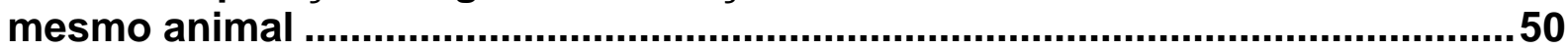

3.4.3 Comparação do grau da doença entre os diferentes grupos ...................50

3.4.3.1 Comparação do grau da doença com relação à idade .................................50

3.4.3.2 Comparação do grau da doença com à raça ............................................51

4 RESULTADOS

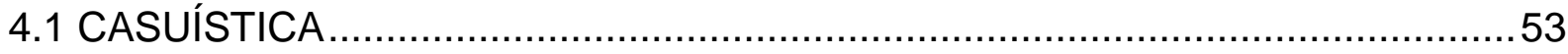

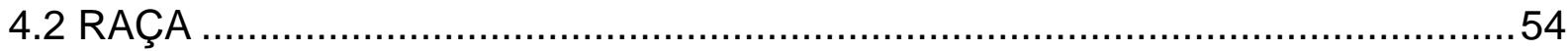

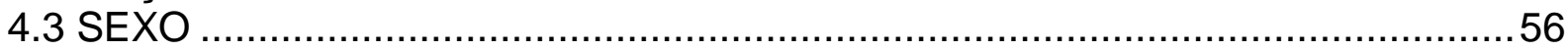

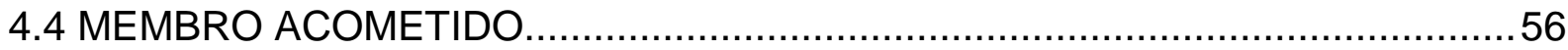

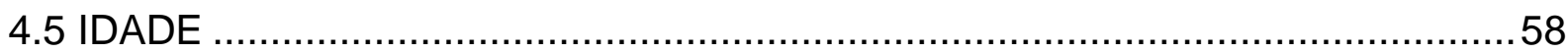

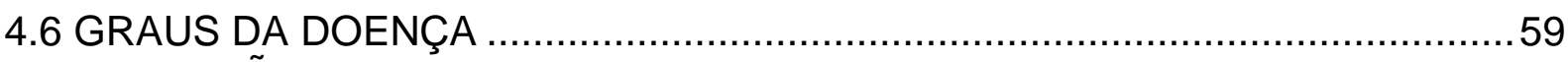

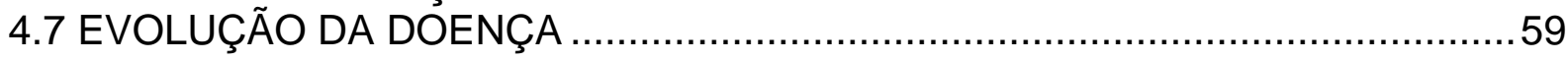

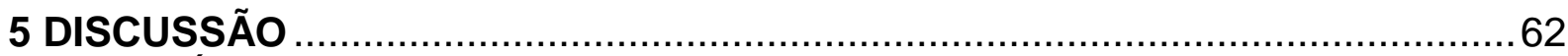

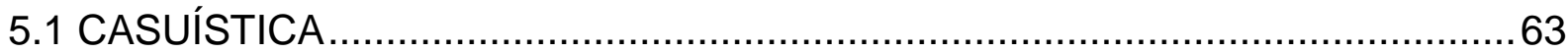

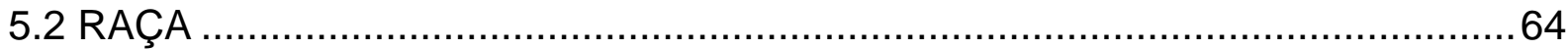

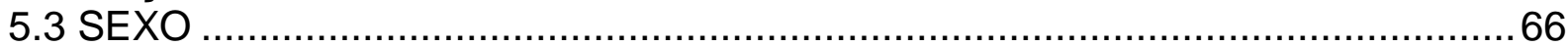

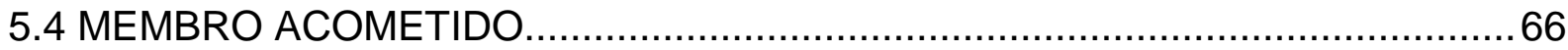

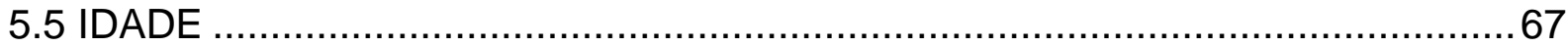

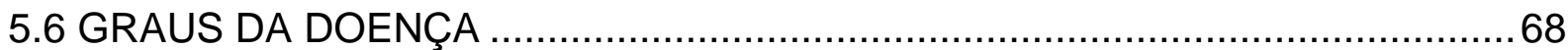

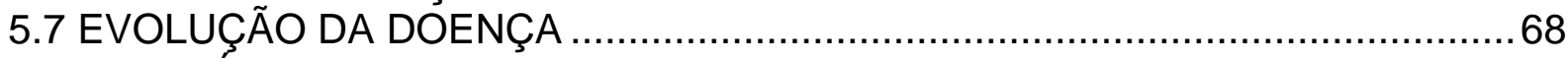

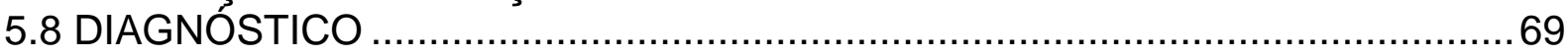

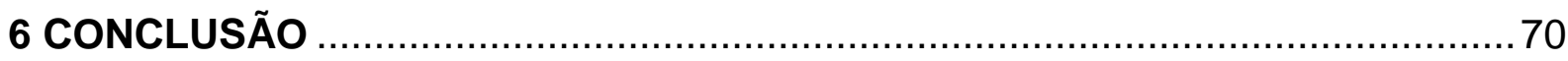

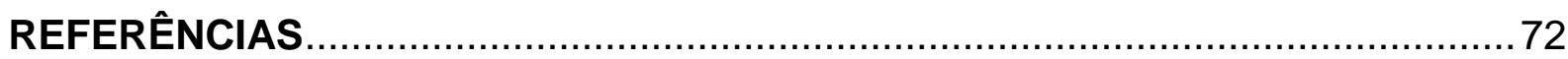




\section{INTRODUÇÃO}

Necrose asséptica da cabeça do fêmur também conhecida como doença de Legg-Perthes, doença de Legg-Calvé-Perthes, necrose isquêmica (avascular) da cabeça femoral, osteocondrite dissecante juvenil, osteocondrose ou coxaplana é uma necrose asséptica não inflamatória da cabeça femoral que ocorre em pacientes jovens antes do fechamento da epífise da cabeça femoral. É uma doença relativamente incomum, que acomete cães jovens (4-11 meses de idade) e de raças"toy" e de pequeno porte. O quadro clínico típico inicia-se com uma dor no quadril e claudicação pélvica progressiva, que resultam em incapacidade parcial ou completa de suportar o próprio peso sobre o membro afetado.

As radiografias mostram deformidades da cabeça femoral, encurtamento do colo femoral e focos de menor radiopacidade óssea na epífise femoral.

Tendo em vista a escassez de estudos atuais sobre o tema, este trabalho tem como objetivo fazer em estudo epidemiológico, tentar descobrir se há uma lateralidade nesses cães, estudar a evolução da doença e classificar radiograficamente as lesões da cabeça femoral, conforme proposto por Ljunggren em 1967, na tentativa de se compreender mais sobre a necrose asséptica da cabeça femoral em cães. 


\section{REVISÃO DE LITERATURA}

\subsection{HISTÓRIA}

A doença de necrose asséptica da cabeça femoral (NACF), ou doença de Legg-Calvé-Perthes (LCP), tem sido bem estudada na medicina, mas há poucos relatos (como foi descoberta, as hipóteses etiológicas sugeridas antigamente, quem foram os primeiros pesquisadores a estudarem a doença). Baseado em escassos relatos e artigos disponíveis, Wenger e Pandya (2011) escreveram uma breve história da doença de Legg-Calvé-Perthes.

$\mathrm{Na}$ medicina do século 19 houve uma evolução significativa dos estudos ortopédicos, especialmente na Alemanha, França e Áustria, mesmo antes da descoberta dos raios-x. Com a crescente utilização da anestesia geral, a exploração cirúrgica do quadril levou a uma ampla compreensão das doenças do mesmo. O conhecimento das doenças do quadril na infância permaneceram bastante limitadas. Se conhecia bem a sepse do quadril e tuberculose, os quais foram facilmente reconhecidos devido à destruição significativa da articulação do quadril. Foi a partir do estudo das infecções do quadril em crianças que se descobriu a doença que hoje conhecemos como a doença de Legg-Calvé-Perthes. (WENGER; PANDYA, 2011)

Ao realizar uma análise histológica detalhada de tuberculose no quadril no final dos anos de 1800, Rokitansky, patologista ósseo vienense renomado, descreveu uma forma mais branda da doença do quadril em crianças que se aproximava do que hoje chamamos de doença de Legg-Calvé-Perthes. (WENGER; PANDYA, 2011) A descoberta dos raios-x pelo físico, Wilhelm Conrad Roentgen, na Alemanha em 8 de novembro de 1895 (THRALL; WIDMER, 2002), revolucionou o mundo ortopédico, especialmente na compreensão das doenças do quadril em crianças. Poucos meses depois, na época do Natal de 1895, em Würzburg, Alemanha, os aparelhos de raios$x$ foram instalados na maioria dos hospitais das principais cidades europeias. (WENGER; PANDYA, 2011)

Foi durante esta época, em 1905, que Kohler fez uma descrição inicial das alterações radiográficas que hoje conhecemos como doença Legg-Calvé-Perthes, no entanto, seu relatório não foi amplamente reconhecido. 
A primeira descrição formal da doença ocorreu quase simultaneamente em 1909 e 1910 por Arthur Legg em Boston, Jacques Calvé na França e pelo alemão Georg Perthes (Figura 1), todos sugerindo etiologias diferentes da doença. Legg apresentou uma série de pacientes que claudicavam e com achatamento das cabeças femorais, acreditava ser secundário à trauma. Calvé relatou 10 pacientes com dor no quadril não-inflamatória e achatamento da cabeça femoral, que ele acreditava ser devido à osteogenese anormal. Finalmente, Perthes relatou em 6 pacientes com dor no quadril que ele acreditava ser devido a uma condição inflamatória. Ao mesmo tempo, da Suécia, Waldenström (Figura 2) descreveu as características radiográficas desta doença atribuindo-as à tuberculose. (WENGER; PANDYA, 2011)

Figura 1 - Os primeiros autores que descreveram a doença. Da esquerda para a direita, Arthur Legg (Estados Unidos), Jacques Calvé (França) e Georg Perthes (Alemanha), respectivamente.
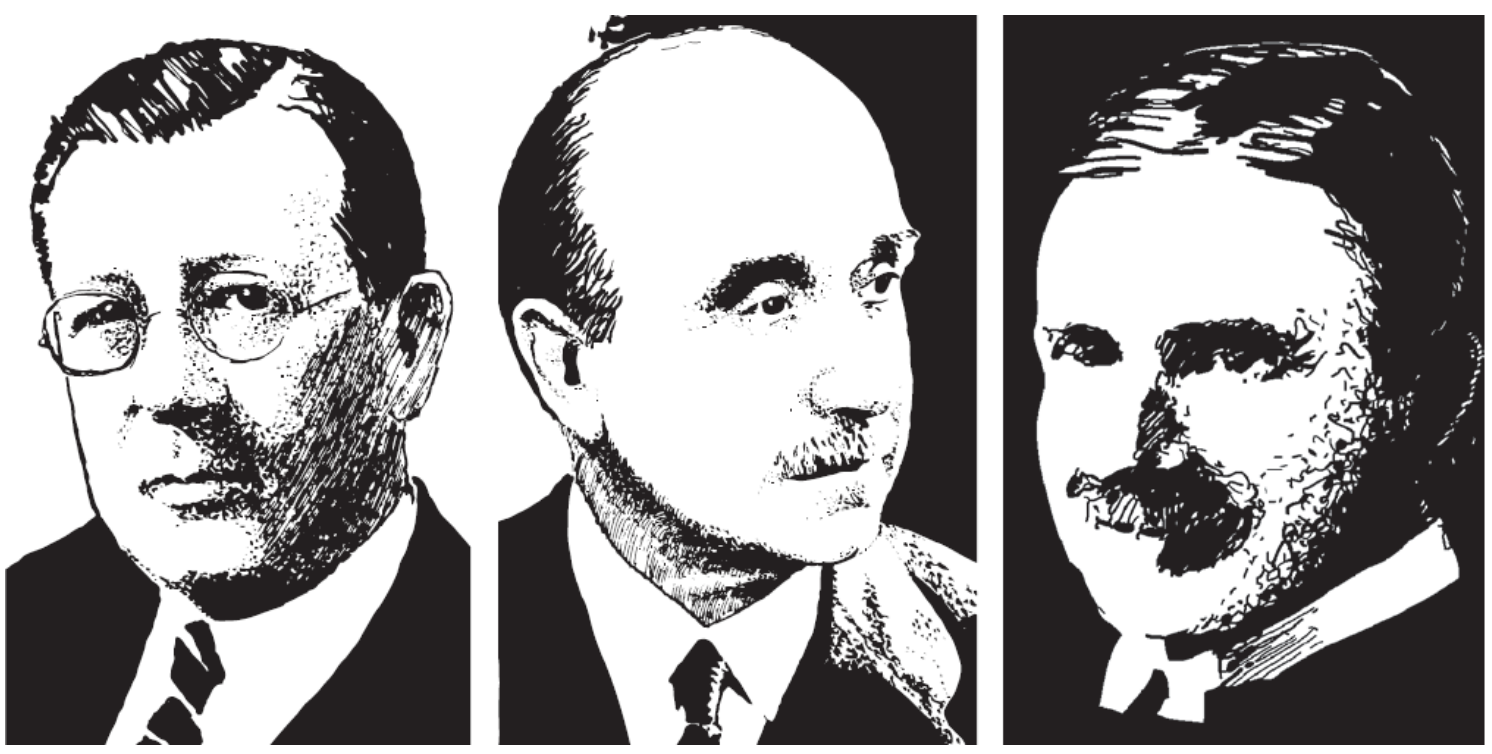

Fonte: WENGER; PANDYA, 2011 
Figura $2-\mathrm{H}$, Waldenström (Suécia) descreveu as características radiográficas desta doença, porém atribuindo-as à tuberculose.

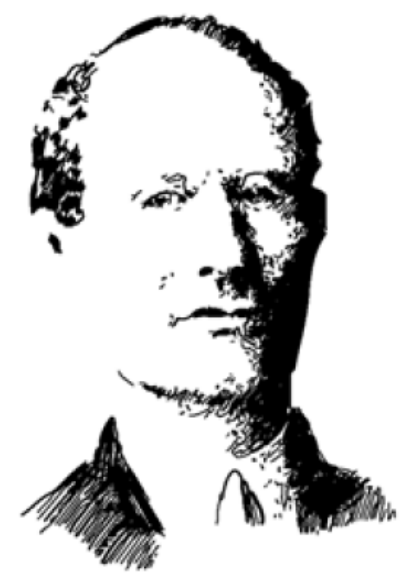

Fonte: WENGER; PANDYA, 2011

Inicialmente, a doença descrita por Legg, Calvé e Perthes foi agrupado na categoria geral de osteocondrite do quadril pediátrico (naquela época, todas as anomalias de crescimento e forma óssea infantil eram classificadas desta forma). No entanto, a verdadeira etiologia permaneceu desconhecida. Não se sabia se era causada por uma doença embólica, hiperemia, trauma, disfunção endócrina, infecção ou uma deficiência de suprimento sanguíneo. (WENGER; PANDYA, 2011)

Estudos histológicos forneceram uma melhor compreensão da patofisiologia da doença de LCP, e uma compreensão subsequente das fases radiográficas da doença. Em 1921, em Chicago, Phemister curetou a parte proximal do fêmur de um menino de 10 anos de idade, com sintomas de claudicação e fez o estudo histológico. Ele descobriu a combinação de osso necrótico e osso cicatricial intercalados com tecido de granulação e osteoclastos. Isso confirmava que as alterações radiográficas na doença de LCP eram provavelmente devido à necrose asséptica seguida por uma fase cicatricial em que ocorreu a revascularização. Esta seqüência histológica foi descrita como "Schleichende Ersetzung" pelos alemães (posteriormente interpretada por Phemister como "substituição deformante"), na qual o osso foi reabsorvido pelos osteoclastos e, em seguida substituído por osso novo pelos osteoblastos. Phemister acreditava que os resultados encontrados por ele eram devido tanto à um processo inflamatório quanto infeccioso, e que a verdadeira etiologia permanecia sem resposta. (WENGER; PANDYA, 2011)

Uma interrupção no suprimento sanguíneo para a cabeça femoral também foi proposta e hoje tem sido a principal e mais importante etiologia sugerida para a 
doença de LCP. Konjetzny (1926) foi o primeiro a mostrar que uma interrupção do suprimento vascular da cabeça femoral estava presente na doença de LCP. Theron estudou a obstrução da artéria retinacular superior, Atsumi pesquisou a interrupção da artéria epifisária lateral, enquanto Sanchis e Inoue a teoria do duplo infarto, e Kleinman e Bleck estudaram o aumento da viscosidade sanguínea. Atualmente, trombofilia (devido à disfunção dos níveis de proteína C e S) está sendo postulado como um possível fator levando a trombose vascular e osteonecrose subseqüente (WENGER; PANDYA, 2011).

Na medicina veterinária, a NACF foi descrita pela primeira vez em literatura por Tutt (1935), ele descreveu a doença, como Waldenstrom fez em 1909 em humanos, como uma tuberculose do quadril. Schnelle (1937), Moltzen-Nielsen (1938) e Olsson (1958) foram os primeiros autores que estudaram amplamente a doença de LCP em cães. Estudaram alguns aspectos como, idade mais acometida, distribuição sexual, lado do membro acometido pela doença, alguns aspectos histológicos, a importância do exame radiográfico e tratamentos na doença de LCP (LJUNGGREN, 1967).

\subsection{ANATOMIA}

Um completo conhecimento da osteologia normal do quadril é essencial para uma conveniente interpretação de anatomia radiográfica, especialmente nos cães, por causa das doenças que acometem a articulação coxofemoral. (GETTY, 1986)

O acetábulo é uma cavidade cotilóide (em forma de taça) que aloja a cabeça do fêmur e orienta-se ventrolateralmente. A parte articular é semilunar e está interrompida internamente por uma depressão rugosa não articular, a fossa acetabular. A parte medial da borda é correspondentemente interrompida pela incisura acetabular. (GETTY, 1986). A superfície acetabular é ampliada por um lábio articular contínuo com o ligamento acetabular transverso que transpôe a incisura, obstruindo a parede medial da cavidade. As paredes da cavidade articular são completadas por uma membrana sinovial sustentada externamente por um revestimento fibroso. Embora a cápsula fibrosa não seja uniformemente forte, não existem quaisquer espessamentos tão delimitados que necessitem ser identificados como ligamentos específicos. Entretanto, a cabeça do fêmur une-se ao fundo do 
acetábulo pelo ligamento intracapsular desta cabeça, o qual é revestido por uma reflexão da membrana sinovial. Em algumas espécies, sabe-se que este ligamento conduz vasos sanguineos, mas a importância dos mesmos quanto à nutrição da cabeça femoral permanece incerta (DYCE et al., 2002).

A articulação coxofemoral possui maior amplitude e versatilidade de movimento no cão e no gato do que em outras espécies domésticas. O maior potencial para abdução é demonstrado pela facilidade com que os cães levantam seus membros pélvicos quando estão urinando e pela amplitude de movimento que permitem alcançar a cabeça e tórax para se coçarem. A cabeça do fêmur é um hemisfério quase perfeito, se não fosse pela pequena fóvea central, onde se insere o ligamento intracapsular (da cabeça do fêmur). Fica profundamente assentada dentro do cálice acetabular. Não existem ligamentos periféricos limitando o movimento. O ligamento intracapsular, embora de comprimento e espessura variáveis é, em geral, suficientemente frouxo para persistir intacto quando a cabeça é luxada (DYCE et al., 2002).

Em animais jovens, existem centros primários de ossificação no ílio, ísquio, púbis e osso acetabular, e centros secundários na crista ilíaca, tuberosidade isquiática e borda do arco isquiático. O osso acetabular é o primeiro a perder sua independência, mas isto é seguido pela fusão dos outros centros primários, em uma idade comparativamente precoce (4 a 6 meses). Os centros secundários permanecem distintos até muito mais tarde (15 meses a 5 anos, para a crista ilíaca, e 8 a 14 meses para a tuberosidade isquiática). A fusão na extremidade proximal do

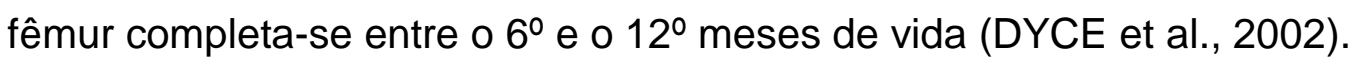

O suprimento sanguíneo da cabeça e colo femoral é fornecido principalmente pelas artérias femorais circunflexas laterais e mediais (BASSET et al., 1969; SLATTER, 2003) e, em menor grau, as artérias glútea caudal, glútea cranial e iliolombar contribuem para o envolvimento do anel vascular extracapsular, que circunda o colo do fêmur. Esse anel vascular irriga inúmeros vasos cervicais ascendentes, que são intracapsulares, mas subsinoviais. Esses vasos cervicais ascendentes ramificam-se em anel vascular intracapsular, que circunda o colo femoral adjacente a fise. A rede vascular ascendente deve atravessar a borda periférica da fise em localização subsinovial para promover a irrigação da epífise proximal em cães imaturos. Alguns cães desenvolvem necrose completa da epífise, enquanto outros apresentam um processo necrótico discreto ou nulo do osso 
epifisário. Apesar disso, após a separação e reparo da fise, dentro de 3 a 8 semanas ocorre a revascularização de epífise proximal femoral completamente desvitalizada. Grande parte das separações da fise proximal femoral estabilizada por via cirúrgica em cães exibe consolidação sem sofrer lise e colapso macroscópicos da epífise (SLATTER, 2003).

A artéria femoral circunflexa medial ramifica-se diretamente da artéria femoral, passa superficialmente ao músculo iliopsoas e profundamente ao músculo pectíneo, terminando ao fazer uma anastomose com as ramificações terminais da artéria femoral circunflexa lateral, formando uma artéria semicircular na região da fossa trocantérica (Figura 3) (BASSET et al., 1969).

A artéria circunflexa lateral do fêmur fornece a maior parte do fluxo arterial para a epífise femural, seu ramo principal irriga a porção posterior do colo femoral, trocanter maior e fossa trocantérica. As ramificações terminais acabam na região basilar do colo femural e extremidade proximal da diáfise femural. Vários ramos da porção terminal da artéria femoral circunflexa lateral penetram diretamente na porção caudoproximal da cápsula articular do coxal e ascendem no colo femoral como a artéria retinacular superior (Figura 4) (BASSET et al., 1969).

A artéria retinacular inferior, é uma ramificação da artéria circunflexa medial do fêmur (Figura 3) e se diferencia das demais artérias retinaculares por ter um rumo extra-articular na porção medial da cápsula antes de penetrar na mesma (Figura 5). Em contra partida, a artéria retinacular superior é a ramificação terminal da artéria circunflexa lateral do fêmur. Todos os vasos retinaculares passam por todo o colo femoral, atravessam a placa de crescimento epifisário até a periferia e depois penetram na epífise. Geralmente eles entram na epífise um ou dois milímetros acima da placa e da metáfise, porém essa distância pode variar (BASSET et al., 1969). 
Figura 3 - Trajetos extra-articulares e intra-articulares da artéria femoral circunflexa medial e suas ramificações. Figura da direita demonstra a principal distribuição das artérias retinaculares inferiores.

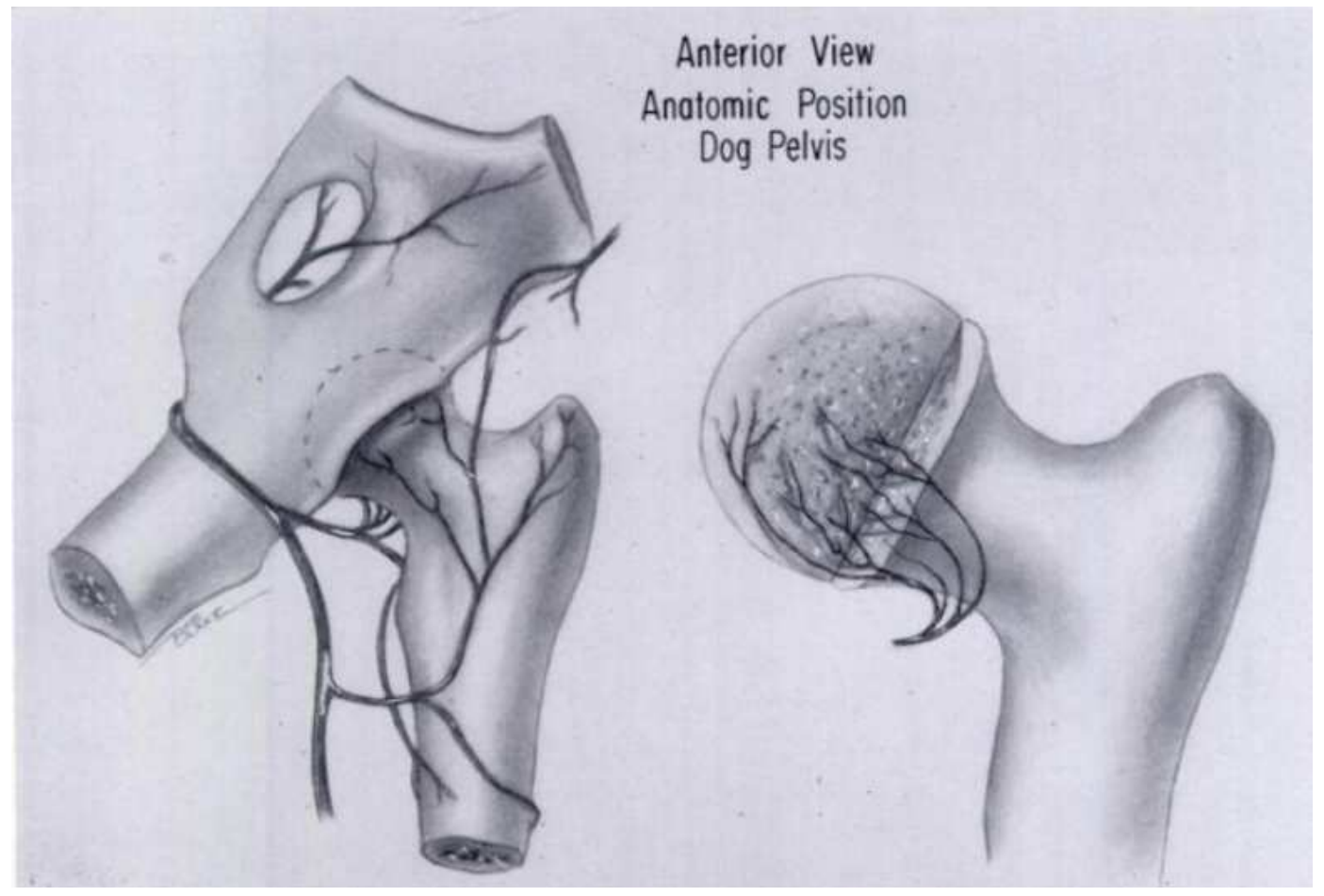

Fonte: BASSET et al., 1969 
Figura 4 - Ramo principal da artéria circunflexa lateral do fêmur irrigando a porção posterior do colo femoral, trocanter maior e fossa trocantérica. Figura à direita demonstra diversos ramos da artéria femoral circunflexa lateral penetrando na cápsula articular e ascendendo como artérias retinaculares superiores.

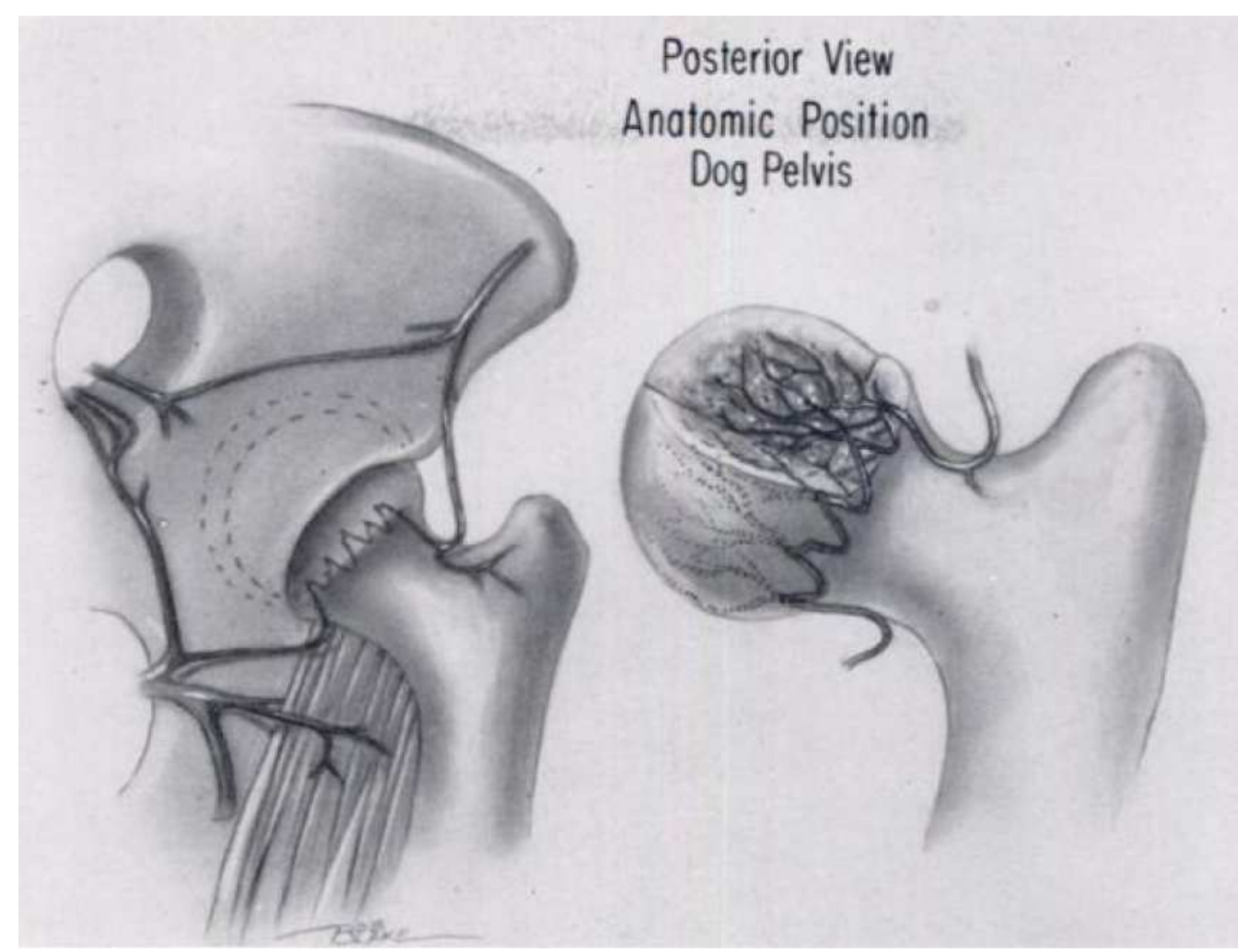

Fonte: BASSET et al., 1969 
Figura 5 - A, B e C, dissecação da musculatura para expor os vasos retinaculares inferiores. D, trajeto dos vasos retinaculares inferiores descendendo da cápsula articular e se inserindo na artéria circunflexa medial.

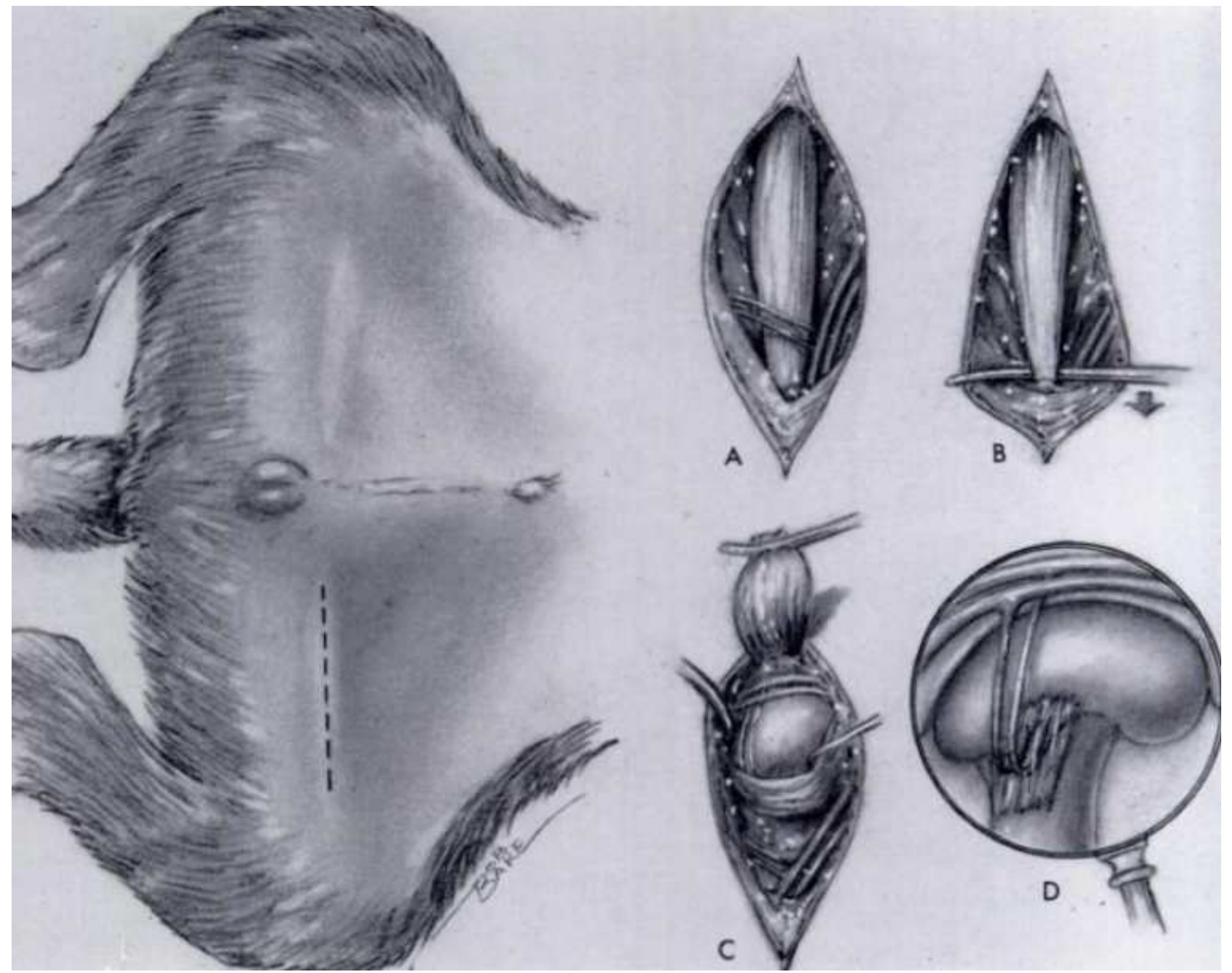

Fonte: BASSET et al., 1969

Com base no tamanho das ramificações das circulações intraepifisárias, Basset et al. (1969), estimaram que o grupo de vasos retinaculares superiores suprem cerca de $70 \%$ da epífise, principalmente a porção lateroproximal. Já as artérias retinaculares inferiores e anteriores preenchem os 30\% remanescentes na porção mediodistal.

A porção proximal da metáfise femoral é irrigada por inúmeras arteríolas metafisárias, que ingressam no osso através de múltiplos forames nutrícios. A rede vascular cervical ascendente derivada dos vasos femorais circunflexos laterais, medial e glúteo caudal também tem contribuição direta na região do colo femoral. Os vasos metafisários unem-se por anastomose por via intra-óssea aos ramos ascendentes da artéria nutrícia principal (ramo terminal da artéria femoral circunflexa medial), que penetra no fêmur através do forame nutrício principal sobre a face 
caudal da diáfise femoral. Assim que ocorrer o fechamento da fise proximal femoral, os vasos metafisários sofrem anastomose com vasos epifisários (SLATTER, 2003).

Resumindo, o principal suprimento sanguíneo da cabeça femoral provém das artérias cervicais ascendentes (ramos das artérias circunflexos laterais) que percorrem ao longo do colo femoral subsinovialmente. A fonte de suprimento sanguíneo secundário é a artéria circunflexa medial, que fornece um abastecimento parcial para a cabeça e colo femoral. A doença de Legg-Calvé-Perthes é uma necrose avascular da epífise proximal do fêmur que está em fase de crescimento, provavelmente causada por uma interrupção do suprimento sanguíneo das artérias retinaculares (ramos das artérias cervicais ascendentes) e diminuição do fluxo sanguíneo na artéria circunflexa medial (DORIA et al., 2008).

Ao contrário das artérias, as veias são tortuosas. Veias subarticulares se apresentam imediatamente abaixo da placa do osso subcondral como numerosos canalículos, formando diversas vias de drenagem da cabeça femoral. As veias geralmente estão paralelas às artérias e são mais calibrosas, vão da periferia da placa epifisária descendo ao longo do colo femoral (BASSET et al., 1969).

A porção proximal do fêmur possui três proeminências ósseas, que se constituem em pontos de inserção muscular. A mais ampla dessas proeminências, 0 trocanter maior, corresponde à inserção dos músculos glúteo médio, glúteo profundo e piriforme. O trocanter menor, situado mediodistalmente ao colo, representa o ponto de inserção para o músculo ilipsoas. O terceiro trocanter, a menor protuberância na face lateral da porção proximal do fêmur situada distalmente ao trocanter maior, é o local de inserção do músculo glúteo superficial. A fossa trocantérica está situada caudalmente no colo femoral, sendo o local da inserção dos músculos obturador interno, obturador externo e gêmeos. O nervo ciático passa sobre a borda dorsal do ísquio e segue rumo à incisura, próximo à face caudal do acetábulo (SLATTER, 2003).

\subsection{Definição}

A necrose asséptica da cabeça do fêmur é também conhecida como doença de Legg-Perthes, doença de Legg-Calvé-Perthes, necrose isquêmica (avascular) da 
cabeça femoral, osteocondrite dissecante juvenil, osteocondrose e coxaplana (KEALY; MCALLISTER, 2000).

É uma doença auto limitante do quadril em desenvolvimento, caracterizada por necrose asséptica da cabeça do fêmur, seguida por fratura subcondral, fragmentação, revascularização e remodelação. (CATTERALL, 1971) O suprimento sanguíneo inadequado na epífise femoral causa a necrose do osso subcondral, enquanto a cartilagem articular continua crescendo, sendo a revascularização, uma tentativa de reparar o defeito. Caso a reparação não seja feita, ocorre a remodelação da cabeça femoral (WISNER; KONDE, 2002).

\subsection{ETIOLOGIA}

Muitas foram as etiologias atribuídas a necrose asséptica da cabeça femoral, como trauma, fatores nutricionais, infecção, distúrbios endócrinos, vasculares (HICKMAN; SPICKETT, 1965), aumento dos hormônios sexuais (LJUNGGREN, 1967), conformação anatômica (BASSET et al., 1969), tamponamento intracapsular e obstrução da drenagem venosa do colo e cabeça femoral (LIU, 1991), mas a distribuição da incidência indica que um fator hereditário está presente (HICKMAN; SPICKETT, 1965).

Até os dias de hoje, não há uma teoria única sobre a causa que leva à obstrução transitória da circulação na cabeça femoral. Dentre as especulações, encontram-se trombofilia, aumento de viscosidade sanguínea, aumento da pressão hidrostática intracapsular (sinovite transitória) e alterações lipídicas (GUARNIERO et al., 2005).

Há também referências a uma possível origem genética (ROBINSON, 1992), como mostra Hickman e Spickett (1965) em seus estudos com poodles miniatura. Pidduck e Webbon (1978) concluem que o defeito é consistente com a hereditariedade de um gene recessivo autossômico. Além de Poodles, a herança autossômica recessiva tem sido sugerida em várias raças, incluindo Yorkshire Terrier, West Highland White Terrier, Poodle Toy, Pug (BOWLUS et al., 2008), schnauzer, pequinês (JONSON; WATSON, 2005) e chihuahua. (OWENS, 1982) Porém, existem outras variáveis, tais como peso corporal, taxa de crescimento e 
influências ambientais (dieta e exercícios) que podem contribuir para essa síndrome (PIDDUCK; WEBBON, 1978).

Em humanos, foi relatado que a hipercoagulabilidade pode causar uma oclusão trombótica das veias da cabeça femoral com hipertensão venosa e morte do osso por hipóxia, levando a doença de LCP. Coagulação anormal devido a deficiência de proteína $C$, deficiência de proteína $S$, ou resistência a proteína $C$ ativada foram observados em 78\% das crianças com LCP (GLUECK, 1997). Brenig et al. (1999) testaram os fatores de coagulação do sangue (proteína C, proteína $S$, proteína C ativada, fator II, fator V, Fator VIII e AT III) em 18 cães com doença de LCP e descobriram que esses fatores tinham uma atividade normal, mostrando que a hipercoagulabilidade ou hipofibrinólise não parecem ser fatores etiológicos na doença de LCP canino.

O suprimento vascular da cabeça femoral é derivado apenas dos vasos epifisários, que entram na epífise ao longo das margens da inserção da cápsula articular. Como os animais afetados são imaturos e tem as metáfises normais, elas agem como barreiras e não permitem a anastomose vascular da região metafisária, fazendo com que os vasos metafisários não vascularizem a cabeça femoral. Portanto, o comprometimento de toda ou parte dos vasos sanguíneos epifisários pode causar uma isquemia completa ou parcial na epífise esponjosa e na medula (TROSTEL; POOL; MCLAUGHLIN, 2003).

Sinovite ou uma posição de sustentação anormal do membro pode causar aumento da pressão intra-articular da coxofemoral, suficientes para colapsar as frágeis veias e inibir o fluxo sanguíneo (WARREN; DINGWALL, 1972).

Como a necrose asséptica da cabeça femoral acomete em grande escala as raças pequenas e animais que estão em fase de crescimento, Ljunggren (1967) resolveu estudar a maturação da cabeça femoral nos cães, com ênfase na morfologia e nas influências hormonais. O autor descobriu que o fechamento do disco de crescimento epifisário começa a partir dos 4 meses de idade em cães de raças pequenas e a partir de 7 meses em cães de tamanho normal, ou seja, 0 fechamento do disco epifisário proximal do fêmur ocorre antes nas raças pequenas do que nas raças de tamanho normal. Porém, o tempo que o disco de crescimento leva para se fechar é o mesmo tanto em raças pequenas quanto em raças de tamanho normal. O retardo e a interrupção do crescimento longitudinal dos ossos é uma das funções dos hormônios sexuais, portanto o fechamento dos discos 
epifisários estão diretamente ligados às atividades dos hormonios sexuais. Ljunggren descobriu que os cães de raça pequena apresentam o primeiro cio antes que os de raça de tamanho normal.

\subsection{MACROSCOPIA E HISTOLOGIA}

Os estudos macroscópicos da cabeça femoral dos cães acometidos revelam que nos casos incipientes, a articulação e os tecidos adjacentes estão hiperêmicos e que o líquido sinovial está claro e límpido. Nos casos mais crônicos, a cápsula articular está espessa, a superfície articular áspera e irregular, e pode haver aumento da viscosidade do líquido sinovial. Nos casos avançados, a cabeça femoral e a superfície articular estão completamente achatadas e deformadas (WARREN; DINGWALL, 1972). Além destes aspectos, Ljunggren (1967) descreveu que em alguns casos o ligamento intracapsular estava aderido à face medioproximal do fêmur e que em um caso, não foi possível visualizar a cápsula articular nem líquido sinovial, em vez disso, observou-se um tecido fibroso entre o que restava da cabeça femoral e o acetábulo correspondente.

Com base em estudos histológicos, Ljunggren (1967) confirmou que a formação excessiva de osso endosteal constitui o início das alterações morfológicas na doença de LCP e que a necrose da medula e do tecido ósseo são as próximas alterações a aparecerem.

O fechamento do disco de crescimento é um evento fisiológico, porém quando ocorre muito cedo se torna patológico. Assim como o crescimento endosteal, que fisiologicamente continua após a parada de crescimento longitudinal dos ossos se transforma em um processo patológico se ocorrer muito cedo ou em excesso (LJUNGGREN, 1967). 


\subsection{EPIDEMIOLOGIA}

A doença de Legg-Calvé-Perthes é relativamente rara, mas têm sido descrita em humanos e cães. A incidência em humanos é de 1: 3.000 em meninos e 1: 11.000 em meninas. Nos cães a incidência atual é desconhecida, mas sabe-se que acomete cães jovens e das raças "toy" e "terrier" (BRENIG et al., 1999).

Um estudo retrospectivo realizado num hospital veterinário universitário brasileiro demonstrou a incidência das diversas afecções ortopédicas dos membros pélvicos em cães. Foram estudados 889 animais em um período de sete anos e dentre as doenças com menor prevalência, a necrose asséptica da cabeça femoral representou $1,5 \%(n=13)$ dos casos, confirmando a baixa incidência da doença (SOUZA et al., 2011).

\subsection{DIAGNÓSTICO}

O diagnóstico da doença de Legg-Clavé-Perthes é geralmente feito com uma boa anamnese, exame físico e confirmado por radiografia (GAMBARDELLA, 1993).

O quadro clínico típico inicia-se com dor no quadril e claudicação pélvica progressiva, que resultam em incapacidade parcial ou completa de suportar o próprio peso sobre o membro afetado (BOWLUS et al., 2008). Ao exame físico notase dor ao manipular a articulação afetada, limitação da amplitude de movimentos, atrofia muscular e crepitação podem estar presentes na doença avançada (HULSE; JOHNSON, 2002). O aparecimento desses sinais pode ocorrer entre 3 a 13 meses de idade, não há predileção sexual, e em 83-90\% dos pacientes a doença é unilateral. Aproximadamente $2 \%$ dos cães dentro das raças predispostas são afetados (JONSON; WATSON, 2005).

A radiografia é a modalidade de imagem padrão utilizada para diagnosticar a necrose asséptica da cabeça do fêmur em cães (Figura 6) (JONSON; WATSON, 2005). As alterações radiográficas iniciais incluem áreas irregulares de lise na epífise proximal do fêmur. (OWENS, 1982) Com a incongruência articular, o colapso do osso subcondral da cabeça femoral e com a evolução da doença, há uma 
deformação das superfícies articulares (WARREN; DINGWALL, 1972; BURK; ACKERMAN, 1996) tanto do acetábulo, quanto da cabeça e colo femorais (OWENS, 1982).

Figura 6 - Radiografia das articulações coxofemorais em projeção ventrodorsal, ilustrando áreas líticas associadas à irregularidade da cabeça femoral direita, causando incongruência articular.

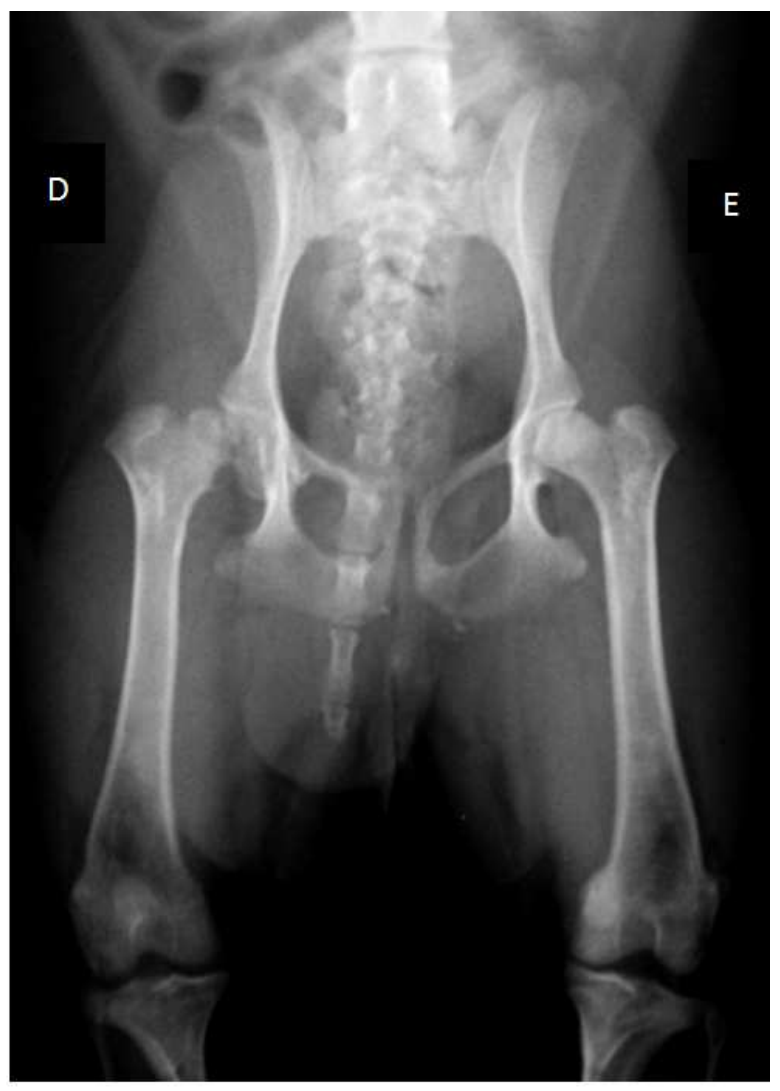

Fonte: Hovet FMVZ-USP, 2010

Nos estudos radiográficos, os diagnósticos diferenciais incluem a artrite séptica, displasia coxofemoral, doença articular degenerativa secundária a fratura traumática, neoplasia (OWENS, 1982) e trauma fiseal (HULSE; JOHNSON, 2002). Lee (1970) comparou os aspectos histológicos e radiológicos em cães com LCP. Após estudar 26 cães, o autor relatou que as alterações iniciais estão na epífise proximal do fêmur, que ainda separados da metáfise por uma placa de crescimento cartilaginosa, por alguma razão torna-se totalmente necrótica, exceto a cartilagem articular. Há provavelmente, nesta fase, pouca ou nenhuma evidência radiográfica de anormalidades e os animais podem também apresentar pouca ou nenhuma claudicação, sendo dificilmente encaminhados para o exame radiográfico nesta fase. 
Apoiando o peso sobre o membro afetado, podem ocorrer microfraturas na região necrótica, formando depressões na porção subcondral do osso, explicando assim a aparência inicial de densidade irregular na radiografia. As microfraturas podem levar a desintegração completa da cabeça femoral. A área mais vulnerável parece ser a região dorsocranial da superfície articular, onde ela está em contato com a margem acetabular dorsal. Concomitante a estas alterações, ocorre a fase inicial de uma reação vascular, com hiperemia da metáfise e perfuração da placa epifisária. Esta resposta vascular provavelmente representa a diferença de densidade óssea na radiografia da região metafisária. A reação vascular invade a epífise, substituindo o tecido necrótico por tecido ósseo novo. O trabeculado necrótico frequentemente persiste até que ocorra a remodelação trabecular, semelhante a "substituição deformante". O trabeculado novo, mais espesso e mais irregular, juntamente com a persistência de tecido fibroso e fibrocartilagíneo, explicaria a persistência das densidades irregulares na radiografia da cabeça e colo femoral nas fases posteriores. O aumento do espaço articular observado radiograficamente e o alargamento do colo femoral podem ser devido a um derrame inflamatório e/ou alterações inflamatórias no ligamento intracapsular, deslocando a cabeça femoral lateralmente. O alargamento do colo femoral pode estar associado ao contínuo processo de revascularização que ocorre na região metafisária e que se torna mais evidente nas radiografias devido ao colapso parcial da cabeça do fêmur. As alterações reativas acetabulares são consequencias de uma doença articular crônica. Lee (1970) conclui que há uma boa correlação entre os aspectos radiográficos e histológicos. No entanto, é difícil determinar o estágio da doença apenas com a imagem radiográfica isolada.

A radiografia convencional mantém sensibilidade para pequenas lesões, tornando-se definitivamente positiva nos quadros iniciais. A especificidade da radiografia simples para alterações avançadas da osteonecrose é alta, portanto é um exame que continua sendo indicado nos casos em que há suspeita de osteonecrose. Se a radiografia mostra colapso subcondral, exames adicionais têm pouco valor, exceto para avaliação do lado oposto (DOMINGUES; DOMINGUES; BRANDÃO, 2001). 
Domingues, Domingues e Brandão (2001) propõem uma sequência de exames quando há suspeita de osteonecrose em humanos. Primeiramente, todos os casos devem realizar o estudo radiológico. Se a osteonecrose for avançada, prosseguir a investigação não trará grandes benefícios. Mas nos casos em que a radiografia for normal e a suspeita for grande, a ressonância magnética tem indicação, em virtude da sua alta sensibilidade quando comparada às outras modalidades de imagem, possibilitando estimar o tamanho e o local preciso da(s) lesão(ões).

Existem outros métodos de imagem que podem ser utilizados para 0 diagnóstico da NACF. A tomografia computadorizada (TC) é menos sensível do que a ressonância magnética $(\mathrm{RM})$ na detecção da necrose asséptica da cabeça femoral. O primeiro sinal de necrose na TC é o sinal do asterisco, que é uma condensação de trabéculas, semelhante a uma estrela dentro da cabeça femoral (HAAGA, 1996).

A tomografia computadorizada é superior à ressonância magnética na necrose de longa duração por delinear a deformidade estrutural da cabeça femoral, caracterizada por fratura subcondral, colapso e fragmentos intra-articulares (DOMINGUES; DOMINGUES; BRANDÃO, 2001).

A ressonância magnética pode detectar a doença de uma forma mais precoce do que a radiografia convencional. A RM em casos de NACF detecta a morte celular em cerca de 5 a 7 dias após a isquemia. Porém, a qualidade da imagem pode ser afetada pelo tamanho dos pacientes, que limitam o número de imagens obtidas das cabeças femorais (BOWLUS et al., 2008).

A RM é mais sensível do que a TC para o diagnóstico precoce da NACF, mostrando sensibilidade de $97 \%$ e especificidade diagnóstica de 98\% (RESNICK; KANG, 1997). A administração endovenosa do gadolínio como contraste, aumenta ainda mais a sensibilidade diagnóstica. É também eficaz em avaliar o estado da cartilagem articular, derrame articular e o estado da medula óssea, o que não é possível pela radiologia convencional, tomografia e cintilografia (DOMINGUES; DOMINGUES; BRANDÃO, 2001). Futuras aplicações da RM na NACF em cães incluem detectar a doença na fase inicial, em cães que ainda não possuem alterações radiográficas ou alterações mínimas (BOWLUS et al., 2008). 
Kramer et al. (1997) examinaram ultrassonograficamente 546 animais com diversas doenças que envolvem o sistema musculoesquelético. Das 23 (4,2\% do total) afecções do coxal apenas 8 (1,4\% do total) estavam relacionadas a doença de LCP. Os achados ultrassonográficos incluem uma cabeça femoral de margens irregulares, cápsula articular bem espessada e derrame articular evidente. Em casos mais avançados, alterações articulares secundárias podem ser vistas, tais como o acúmulo de fibrina (aspecto irregular e ecogenicidade variada, de hiper a hipoecóica). Instabilidades articulares também podem ser avaliadas ultrassonograficamente através de um exame dinâmico, com movimentos passivos e sutis de rotação, abdução e adução na coxofemoral (KRAMER; 1997).

Quando se trata de doenças ósseas e articulares, a radiologia continua sendo o modalidade de diagnóstico mais usado na rotina veterinária (OWENS, 1982). No entanto, para doenças de tecidos moles, músculos e tendões o ultrassom é mais preciso do que a radiologia. A ultrassonografia é um procedimento complementar para a avaliação óssea, devido a reflexão das ondas de ultrassom sobre as superfícies do osso, sendo visível apenas seu contorno. No entanto, a ultrassonografia pode ser um excelente auxílio nas mãos de um profissional experiente, podendo avaliar derrame articular, alterações da cápsula articular, superfícies articulares, tendões e tecido muscular (KRAMER; 1997).

Em um estudo realizado em cães neonatos, com idade entre um dia e doze semanas, mostrou que com a utilização do ultrassom é possível observar a cabeça femoral, a margem acetabular, o espaço articular e a cápsula articular. A cabeça femoral apareceu como uma estrutura heterogênea arredondada nos cães com um dia de idade. O fluido sinovial é representado por uma área anecóica (GRESHAKE; ACKERMAN, 1992). A ossificação da cabeça femoral progride rapidamente e interfere na avaliação do acetábulo em cães com 6 semanas de idade. Com doze semanas, a cabeça femoral já está bem ossificada impossibilitando a avaliação total do acetábulo. As margens craniais e caudais do acetábulo são facilmente reconhecidas nos planos longitudinais e dorsolaterais. No plano transversal, identifica-se a margem medial do acetábulo, no entanto a margem lateral não pode ser identificada devido à sobreposição da cabeça do fêmur. A cápsula articular pode ser identificada como uma linha hiperecóica, especialmente perto da porção cranial e caudal do acetábulo. É possível observar os movimentos da cabeça femoral dentro do acetábulo. O plano transversal pode ser obtido em filhotes com até quatro 
semanas de idade, após este período, a definição anatômica normal fica difícil devido à ossificação da porção ventral do acetábulo. Os planos longitudinais e dorsolaterais fornecem boas imagens até a oitava semana de idade. Com doze semanas idade, a ossificação da cabeça femoral sobrepõe as estruturas adjacentes (GRESHAKE; ACKERMAN, 1992).

Em um estudo realizado em humanos, Doria (2008) avaliou diversos planos ultrassonográficos com o intuíto de determinar a melhor janela acústica para estudar a vascularização da epífise proximal do fêmur. A autora realizou sete acessos diferentes e concluiu que cada um dos acessos conseguia avaliar melhor uma região específica, ou seja, para otimizar o tempo do exame o profissional poderia utilizar o acesso escolhido e avaliar a região previamente comprometida. E ao final do estudo a autora conclui que com o Doppler de amplitude a ultrassonografia pode se tornar uma técnica de imagem em potencial para acompanhamento e avaliação das vascularizações das lesões de pacientes com doença de Legg-Calvé-Perthes.

Atualmente, existem outros exames de imagem que fornecem informações adicionais ou mais precoces que não são possíveis com o exame radiográfico, porém todos possuem uma limitação (Quadro 1). 
Quadro 1 - Vantagens e desvantagens das diversas modalidades de imagem que podem ser utilizadas na NACF - São Paulo - 2012

\begin{tabular}{|c|c|c|}
\hline Modalidade & Vantagem (ns) & Desvantagem (ns) \\
\hline Raios-x & $\begin{array}{l}\text { Baixo custo (média de } R \$ \\
150,00 \text { ). Excelente exame } \\
\text { para avaliação óssea e } \\
\text { articular. Na maioria das } \\
\text { vezes não requer sedação } \\
\text { ou tranquilização do } \\
\text { paciente. Considerado } \\
\text { exame padrão para } \\
\text { avaliação de NACF. }\end{array}$ & $\begin{array}{l}\text { Lesões muito pequenas } \\
\text { podem não ser detectadas, } \\
\text { tornando-se inviável para } \\
\text { diagnósticos precoces. } \\
\text { Dependendo da região } \\
\text { avaliada, sobreposições } \\
\text { podem ocorrer, dificultando } \\
\text { a avaliação da imagem. } \\
\text { Exposição à radiação } \\
\text { ionizante. }\end{array}$ \\
\hline Ultrassom & $\begin{array}{l}\text { Baixo custo (média de R\$ } \\
150,00 \text { ). Avalia derrame } \\
\text { articular, cápsula articular, } \\
\text { superfícies articulares e } \\
\text { tecidos moles (músculos e } \\
\text { tendões). Com a utilização } \\
\text { do Doppler, é possível } \\
\text { avaliar a vascularização da } \\
\text { cabeçã femoral. Não requer } \\
\text { sedação ou tranquilização. }\end{array}$ & $\begin{array}{l}\text { Trata-se de um } \\
\text { procedimento complementar } \\
\text { ao diagnóstico da NACF. } \\
\text { Não avalia tecido ósseo em } \\
\text { sua totalidade, se visualiza } \\
\text { apenas a superfície óssea. }\end{array}$ \\
\hline $\begin{array}{c}\text { Tomografia } \\
\text { Computadorizada }\end{array}$ & $\begin{array}{l}\text { Sem sobreposições de } \\
\text { imagens, sendo ideal em } \\
\text { casos crônicos (quando há } \\
\text { deformidade da cabeça } \\
\text { femoral ou proliferações } \\
\text { osteofíticas adjacentes), } \\
\text { pois auxilia na detecção de } \\
\text { microfraturas, fragmentos } \\
\text { intra-articulares. }\end{array}$ & $\begin{array}{l}\text { Custo elevado (média de } \mathrm{R} \$ \\
1.000,00 \text { ). Requer anestesia } \\
\text { para realização do exame. } \\
\text { Geralmente, o tamanho dos } \\
\text { pacientes limitam a } \\
\text { qualidade da imagem e o } \\
\text { número de imagens obtidas } \\
\text { da cabeça femoral. } \\
\text { Exposição à radiação } \\
\text { ionizante. }\end{array}$ \\
\hline $\begin{array}{l}\text { Ressonância } \\
\text { Magnética }\end{array}$ & $\begin{array}{l}\text { Diagnóstico muito precoce. } \\
\text { Possibilita avaliação da } \\
\text { cartilagem articular, } \\
\text { derrame articular e medula } \\
\text { óssea. }\end{array}$ & $\begin{array}{l}\text { Custo elevado (média de } \mathrm{R} \$ \\
1.500,00 \text { ). Requer anestesia } \\
\text { para realização do exame. } \\
\text { Geralmente, o tamanho dos } \\
\text { pacientes limitam a } \\
\text { qualidade da imagem e o } \\
\text { número de imagens obtidas } \\
\text { da cabeça femoral. }\end{array}$ \\
\hline
\end{tabular}




\subsection{CLASSIFICAÇÃO}

Hulth, Norberg e Olsson (1962) mostraram os diferentes estágios da necrose asséptica da cabeça femoral em cães, desde o estágio inicial até o grau mais avançado, comparando o tempo de claudicação com os aspectos radiográficos. Um cão claudicando há um mês mostrou apenas discreta radiotransparência focal na cabeça femoral afetada. Outro cão com histórico da doença há quatro meses mostrou achatamento da cabeça femoral, que juntamente com o colo femoral, possuíam grande área irregular quase totalmente radiotransparente. O resto do colo e a parte proximal da diáfise femoral estavam escleróticas. Os sinais radiográficos de um cão que claudicava há seis meses mostraram uma séria deformação da cabeça femoral e do acetábulo correspondente. Era notável que o colo femoral e o acetábulo estavam inclusos no processo patológico.

Ljunggren (1967) descreveu e classificou as lesões em cinco graus (Quadro 2).

\subsection{TRATAMENTO}

O tratamento conservativo (caminhadas curtas várias vezes ao dia, natação, drogas analgésicas quando necessário) produz resultados satisfatórios em $25 \%$ a $30 \%$ dos cães acometidos, ao passo que na excisão da cabeça e colo femorais, quando executadas corretamente, oferece um resultado bom a excelente em $67 \%$ a $85 \%$ dos casos, embora uma discreta claudicação intermitente possa persistir. Caso não ocorra uma melhora clínica com o tratamento conservativo em quatro semanas, aconselha-se a realização da excisão cirúrgica da cabeça do fêmur (JONSON; WATSON, 2005).

Gibson, Lewis e Pechman (1990) descreveram um caso de tratamento conservativo bem sucedido em que o diagnóstico foi precoce, antes de qualquer alteração de remodelamento da articulação do quadril. Foi realizado uma bandagem de Ehmer modificada durante 20 semanas. No entanto, segundo os autores, muitos cães com LCP não são diagnosticados no início da doença, levando a lesões osteoarticulares graves em quase todos os casos. 
A excisão da cabeça e colo femoral continua sendo a forma mais comum de tratamento. Esta cirurgia bem sucedida, alivia a dor e os sinais de claudicação em $84 \%$ a $100 \%$ dos cães, independentemente da idade e do estágio da doença. Os tratamentos cirúrgicos capazes de preservar a articulação da coxofemoral, uma vez que a doença está num estágio avançado, não foram relatados em cães (GIBSON; LEWIS; PECHMAN, 1990).

Nos casos de necrose asséptica da cabeça femoral bilateral, o membro mais acometido pode ser operado primeiro, seguido pela cirurgia do membro contralateral, assim que o primeiro já estiver em uso, porém a cirurgia bilateral simultânea tem tido bons resultados e aparentemente encoraja mais precocemente o apoio dos membros operados (SEER; HUROV, 1968).

A realização de exercício é recomendada logo após a cirurgia. A amplitude de movimento pode ser iniciada imediatamente após a cirurgia com a flexão e extensão suave do quadril. A freqüência e a intensidade da terapia vão aumentando conforme a tolerância do animal. O grau de atrofia muscular no momento da cirurgia, dita a velocidade à qual o cão irá voltar a atividade normal. O prognóstico para o retorno à função normal é de bom a excelente em cães que realizam a cirurgia. Em pacientes que não realizam a cirurgia ou que a cirurgia é realizada inadequadamente, é esperada uma claudicação contínua. Portanto, a técnica adequada na remoção da cabeça e colo femoral é fundamental para o sucesso a longo prazo (TRSOTEL; POOL; MCLAUGHLIN, 2003). 


\section{MATERIAL E MÉTODO}

Foram avaliadas radiografias do arquivo do serviço de Radiologia do Departamento de Cirurgia da Faculdade de Medicina Veterinária e Zootecnia da Universidade de São Paulo de animais encaminhados ao serviço de radiologia com suspeita de Necrose asséptica da cabeça do fêmur no período de janeiro de 2000 a dezembro de 2010.

Essas radiografias são identificadas com o número do prontuário, número da radiografia, raça, sexo, idade do animal e data da realização do exame radiográfico. Para facilitar a localização das radiografias, primeiramente foi realizado um levantamento dos laudos que tinham como diagnóstico ou suspeita diagnóstica a necrose da cabeça femoral nos cães, atendidos no Serviço de Radiologia no período abrangido pelo estudo. Posteriormente, foi feita a busca das imagens referidas para o estudo.

No ano de 2000 a 2001, os laudos eram impressos em papel e arquivados no Departamento de Radiologia da Faculdade de Medicina Veterinário da Universidade de São Paulo. E no período de 2002 a 2010, os laudos eram digitalizados no programa "Access" e salvos em arquivos mensalmente.

No ano de 2009, o Serviço de Radiologia do Hospital Veterinário da Faculdade de Medicina Veterinária e Zootecnia da Universidade de São Paulo foi informatizado e digitalizado, com o equipamento "FCR Capsula X" da marca "FUJIFILM" e o "SYNAPSE FUJIFILM", um sistema de gerenciamento, armazenamento e distribuição de imagens. Portanto, as imagens até 2009, eram radiografias convencionais arquivadas no Departamento de Radiologia, as imagens obtidas a partir desta data, estavam digitalizadas e arquivadas no sistema "SYNAPSE" em formato DICOM.

Após selecionar todos os laudos relacionados à necrose asséptica da cabeça femoral, no período de 2000 a 2010, foi realizada a busca das imagens. As alterações radiográficas na região de cabeça e colo femorais e acetábulo foram avaliadas e classificadas radiograficamente. Além das alterações radiográficas, as informações referentes à raça, sexo, idade, membro(s) acometido(s) e tempo de evolução da doença (apenas nos casos em que foram realizados exames radiográficos controle) foram anotados para a realização do estudo estatístico. 


\subsection{EQUIPAMENTOS RADIOLÓGICOS}

As radiografias foram adquiridas utilizando-se equipamentos radiológicos, das marcas Raytech e Tecno Designer, ambos de alta frequência, TD $500 \mathrm{HF}$, com mesas radiológicas portando grade antidifusora e acoplados ao sistema de radiografia computadorizado Fuji, modelo FCR CÁPSULA $X$ com PC (Personal Computer) e cassetes com placa de fósforo (IP -- Imaging Plate) como detector de raios $X$ nos tamanhos $18 \times 24 \mathrm{~cm}, 24 \times 30 \mathrm{~cm}$ ou $35 \times 43 \mathrm{~cm}$, na dependência do porte do animal em estudo. Os cassetes ou chassis $35 \times 43 \mathrm{~cm}$ são pouco utilizados, tanto que no presente estudo utilizou-se apenas uma vez. As películas radiográficas (imagens analógicas) sofreram um processo de revelação, fixação, lavagem e secagem através de uma processadora automática da marca Macrotec MX2, para a obtenção das imagens em filme radiográfico.

\subsection{TÉCNICA RADIOGRÁFICA}

O posicionamento radiográfico dos animais foi obtido com o auxílio dos proprietários e técnicos de radiologia do Hospital veterinário da FMVZ/USP, devidamente protegidos, de acordo com as normas de proteção radiográfica vigentes. As técnicas radiográficas fundamentaram-se em uma metodologia que relacionou à espessura da região radiografada à quilovoltagem $(k V)$ e a miliamperagem-segundo ( $\mathrm{mAs}$ ).

A projeção realizada foi a ventrodorsal, com o animal em decúbito dorsal, membros posteriores foram tracionados para trás (membros em extensão), fêmores paralelos e com ligeira rotação interna (SCHEBITZ; WILKENS, 2000). 


\subsection{ANÁLISE DOS EXAMES RADIOGRÁFICOS}

As imagens impressas em filme radiográfico (período de 2000 até 2009) foram avaliadas em negatoscópios e as imagens digitalizadas (período de 2009 até 2010) foram estudadas em monitor diagnóstico monocromático LCD com 3 megapixels de resolução de 21.3 polegadas da Marca Eizo modelo Radiforce GS320 ${ }^{1}$. Para a classificação radiográfica dos graus da NACF, se seguiu o que LJUNGGREN (1967) propôs. O quadro 2 descreve as alterações encontradas em cada grau e a figura 7 (A; B; C; D e E) mostra imagens características dos graus de 1 a 5 , respectivamente.

\footnotetext{
${ }^{1}$ EIZO Nanao Corporation. Ishikawa, Japão
} 
Quadro 2 - Classificação e descrição radiográfica das lesões articulares da coxofemoral acometida pela doença de NACF - Copenhagen - 1967

\begin{tabular}{|c|c|}
\hline Grau & Descrição radiográfica \\
\hline $\begin{array}{c}\text { Grau } 1 \\
\text { (Figura 7-A) }\end{array}$ & $\begin{array}{l}\text { - Contorno de cabeça e colo femorais normais; } \\
\text { - Espaço articular visivelmente aumentado; } \\
\text { - Há focos únicos ou múltiplos de diminuição de densidade na } \\
\text { cabeça e, mais raramente, no colo femoral, distal à linha epifisária; } \\
\text { - Acetábulo sem alterações. }\end{array}$ \\
\hline $\begin{array}{c}\text { Grau } 2 \\
\text { (Figura 7-B) }\end{array}$ & $\begin{array}{l}\text { - Nítido achatamento da cabeça femoral; } \\
\text { - Sem evidências de aumento do espaço articular; } \\
\text { - Focos mais numerosos e amplos de diminuição da densidade } \\
\text { causam uma aparência de "roedura de traça". Isto ocorre na } \\
\text { cabeça e colo femorais; } \\
\text { - Na porção craniolateral da borda acetabular frequentemente há } \\
\text { um pequeno osteófito. }\end{array}$ \\
\hline $\begin{array}{c}\text { Grau 3 } \\
\text { (Figura 7-C) }\end{array}$ & $\begin{array}{l}\text { - Alterações de contorno estão mais acentuadas; } \\
\text { - A visualização da cabeça femoral é de moderada a pronunciada } \\
\text { com irregularidade na superfície articular; } \\
\text { - Sem evidências de aumento do espaço articular; } \\
\text { - Persiste a aparência de "roedura de traça"; } \\
\text { - O osteófito acetabular pode estar mais acentuado. }\end{array}$ \\
\hline $\begin{array}{c}\text { Grau } 4 \\
\text { (Figura 7-D) }\end{array}$ & $\begin{array}{l}\text { - Contorno normal da cabeça femoral está completamente perdido; } \\
\text { - Podem ocorrer fragmentações secundárias; } \\
\text { - Sem evidências de aumento do espaço articular; } \\
\text { - Persiste a aparência de "roedura de traça"; } \\
\text { - Somente algumas áreas apresentam densidade normal. } \\
\text { - O osteófito acetabular pode estar mais acentuado. }\end{array}$ \\
\hline $\begin{array}{c}\text { Grau } 5 \\
\text { (Figura 7-E) }\end{array}$ & $\begin{array}{l}\text { - Há extensa fragmentação da cabeça femoral } \\
\text { consequentemente, descontinuidade da superfície articular; } \\
\text { - Acentuadas alterações morfológicas acetabulares; } \\
\text { - O osteófito acetabular pode estar mais acentuado. }\end{array}$ \\
\hline
\end{tabular}

Fonte dos dados brutos: Copenhagen. LJUNGGREN, G., 1967. 
Figura 7 - Imagens radiográficas ilustrando os graus da NACF segundo LJUNGGREN (1967). A. Grau 1: contorno de cabeça e colo femorais normais, com aumento da interlinha radiográfica e áreas radiotransparentes na cabeça femoral esquerda e, mais raramente, no colo femoral. Acetábulo sem alterações. B. Grau 2: nítido achatamento da cabeça femoral direita, sem aumento do espaço articular. Focos radiotransparentes mais numerosos e amplos na cabeça e colo femorais. Presença de pequeno osteófito na porção craniolateral da borda acetabular. C. Grau 3: alterações de contorno mais acentuadas, dificuldade em visualizar a cabeça femoral direita devido a irregularidade na superfície articular. Osteófito acetabular mais evidente. D. Grau 4: contorno normal da cabeça femoral está completamente perdido, podendo haver fragmentações. Somente algumas áreas apresentam densidade normal. E. Grau 5: grande fragmentação da cabeça femoral e acentuadas alterações morfológicas acetabulares do lado direito.
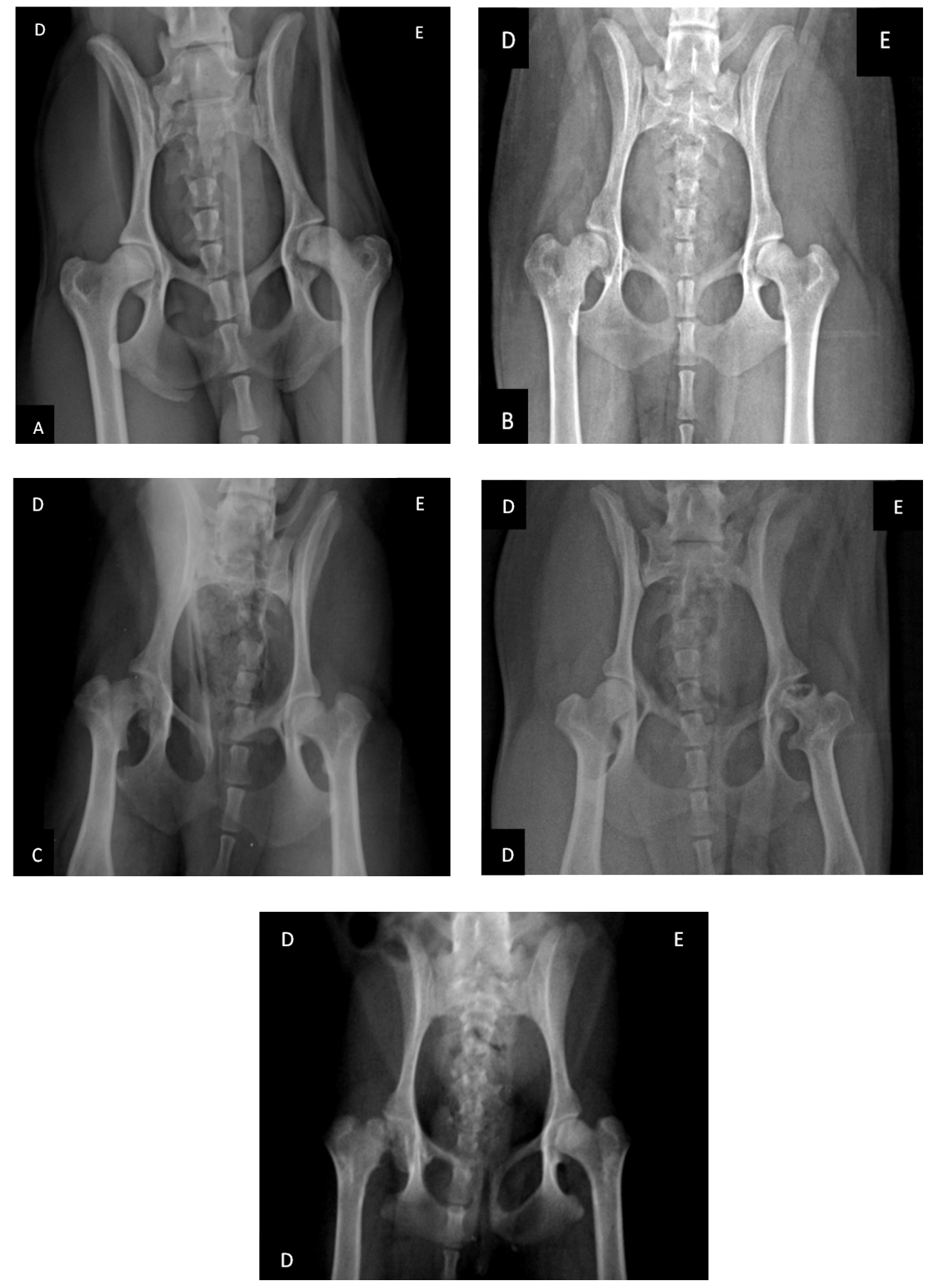

Fonte: Hovet FMVZ-USP, 2010. 
Nos casos em que os animais possuíam os dois membros acometidos, cada membro foi classificado separadamente.

Os dados obtidos (identificação do paciente, raça, sexo, idade, data do estudo ou tempo de evolução da doença, membro(s) acometido(s) e grau da doença classificada radiograficamente) foram inseridos em um quadro (Quadro 3) para serem encaminhados para a avaliação estatística.

Quadro 3 - Dados dos pacientes (identificação, raça, sexo, idade, data do estudo ou tempo de evolução da doença, membro(s) acometido(s) e grau da doença classificada radiograficamente), que foram encaminhados para o estudo estatístico - São Paulo 2012

\begin{tabular}{|c|c|c|c|c|c|c|}
\hline $\begin{array}{c}\text { No do } \\
\text { prontuário }\end{array}$ & Raça & Sexo & Idade & Data & $\begin{array}{c}\text { Membro } \\
\text { acometido }\end{array}$ & $\begin{array}{c}\text { Classificação } \\
\text { radiográfica }\end{array}$ \\
\hline 212497 & Poodle & F & 11 meses & $01 / 10 / 2010$ & E & Grau 2 \\
\hline 212279 & SRD & F & 11 meses & $24 / 11 / 2010$ & D & Grau 3 \\
\hline 213308 & Schnauzer & F & 02 anos & $17 / 11 / 2010$ & D & Grau 4 \\
\hline
\end{tabular}

\subsection{ESTATÍSTICA}

\subsubsection{Estatística descritiva}

Para as variáveis qualitativas, como raça, sexo, membro acometido e o grau da doença, as estatísticas apresentadas foram as frequências absolutas (n) e as frequências relativas (\%). Para as variáveis quantitativas, medidas resumos a média e a mediana e o desvio-padrão, mínimo e máximo para apontar a variabilidade. 


\subsubsection{Comparação do grau da doença entre diferentes membros de um mesmo animal}

Em pacientes com acometimento de ambos os membros, foi utilizado o teste Kappa, para avaliar se o grau de um membro poderia ser igual ao grau do outro ou na ausência de relação entre os membros, se eles poderiam ser avaliados de forma independente. Para tal foi considerado um nível de significância de $5 \%(p<0,05)$.

\subsubsection{Comparação do grau da doença entre os diferentes grupos}

Para as comparações da distribuição do grau da doença entre os grupos de interesse tais como sexo, idade, membro acometido e raça, o teste utilizado foi o Qui-Quadrado. Foi considerado um nível de significância de 5\%. Desta forma, foram consideradas diferenças entre os grupos quando $p$-valor foi menor do que 0,05 ( $p$ valor $<0,05)$.

\subsubsection{Comparação do grau da doença com relação à idade}

Para a comparação de idade, os dados foram divididos em três grupos (menos de um ano, um ano e mais de um ano).

Para a comparação da média de idade entre os diferentes graus da doença, o teste utilizado foi o t-Student, considerando um nível de significância de 5\%. 
3.4.3.2 Comparação do grau da doença com relação à raça

Como para a maioria das raças havia apenas 1 ou 2 animais, impossibilitando as análises, para as comparações as raças foram agrupadas em quatro categorias Pinscher, Poodle, Yorkshire e outros. 


\section{RESULTADOS}

\subsection{CASUÍSTICA}

Todos os laudos relacionados à necrose asséptica da cabeça femoral, no período de 2000 a 2010, totalizaram 170 casos, dos quais foram encontrados 97 imagens (57\% de todos os laudos selecionados). Todas as imagens do "SYNAPSE" pesquisadas foram encontradas, somando 20 casos, representando $100 \%$ das imagens digitalizadas encontradas. As imagens impressas em filmes radiográficos, ou seja, antes de 2009, representavam 150 casos, porém foram encontrados somente 77 casos, representando $51,3 \%$ das imagens impressas em filmes radiográficos (Gráfico 1).

O total de exames relacionados à NACF e o número de imagens encontradas a cada ano estão representadas no gráfico 2 .

Todas as radiografias analógicas impressas em filme radiográfico, se encontravam em excelente estado e sem sinais de deterioração, apresentando uma boa qualidade diagnóstica. 
Gráfico 1 - Quantidade de estudos convencionais e digitalizados e a porcentagem encontrada, São Paulo jan.-2000 I dez.-2010

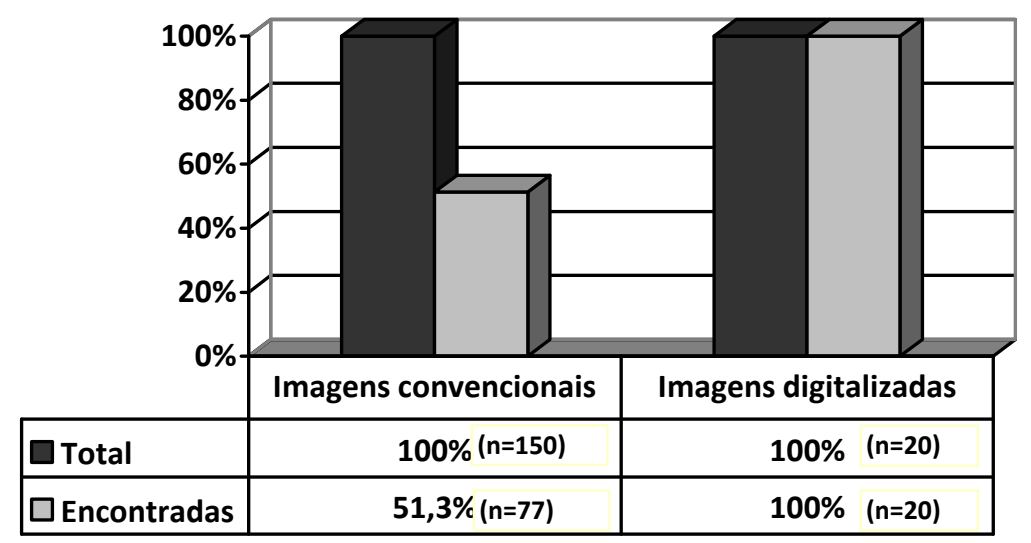

Gráfico 2 - Total de estudos relacionados à NACF e a quantidade encontrada a cada ano, São Paulo - jan.-2000 / dez.-2010

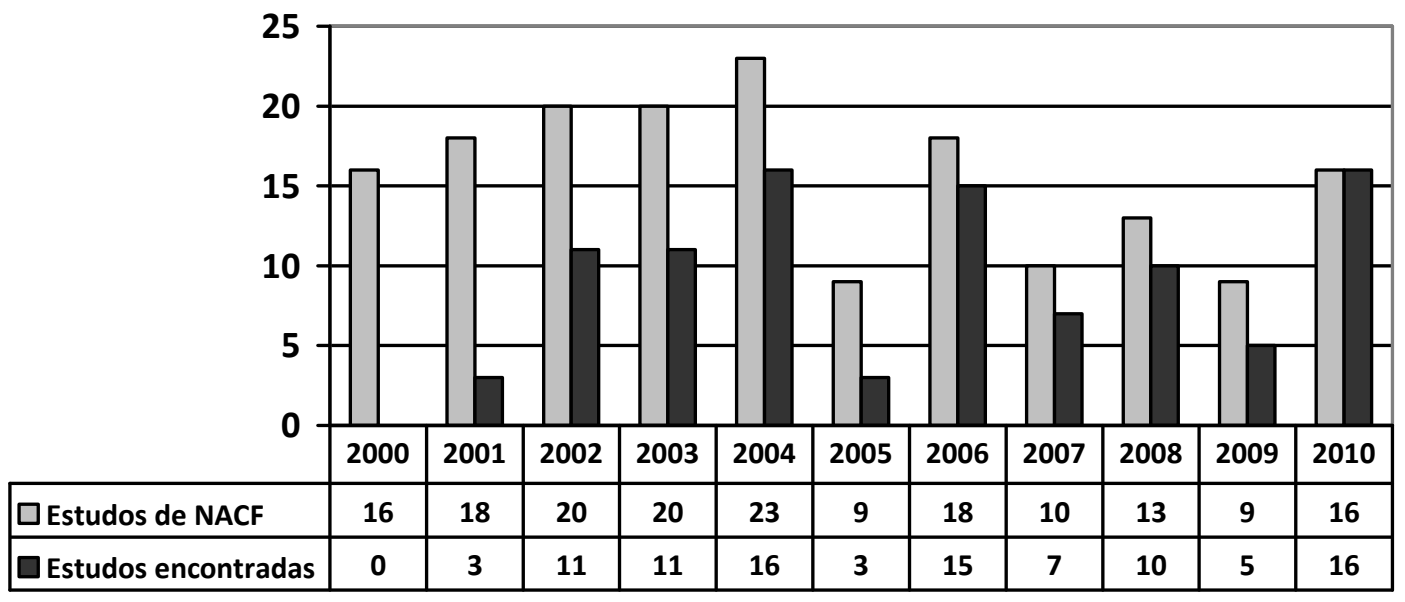

\subsection{RAÇAS}

As principais raças acometidas pela necrose asséptica da cabeça femoral nos cães foram Poodles, Yorkshires e Pinschers. As frequências das demais raças não foram significantemente expressivas (Tabelas 1 e 2).

Quando comparadas aos graus da doença, nota-se que em todos os graus, o maior percentual eram Poodles, porém não houve diferença, estatisticamente significante $(p=0,192)$ (Tabela 3). 
Tabela 1 - Freqüências absolutas (n) e relativas (\%) relacionadas ás raças dos animais estudados, São Paulo - jan.-2000 / dez.-2010

\begin{tabular}{lcc}
\hline Raça & $\mathrm{n}$ & $\%$ \\
\hline Basenji & 1 & 1,0 \\
Chihuahua & 1 & 1,0 \\
Dachshound & 1 & 1,0 \\
Fox Paulistinha & 1 & 1,0 \\
Fox Terrier & 1 & 1,0 \\
Lhasa Apso & 2 & 2,1 \\
Maltês & 2 & 2,1 \\
P.A. & 1 & 1,0 \\
Pinscher & 15 & 15,5 \\
Poodle & 38 & 39,2 \\
Schnauzer & 2 & 2,1 \\
Shih-Tzu & 2 & 2,1 \\
SRD & 8 & 8,2 \\
Yorkshire & 22 & 22,7 \\
Total & 97 & 100,0 \\
\hline
\end{tabular}

Tabela 2 - Grau da doença nas diversas raças, São Paulo - jan.-2000 / dez.-2010

\begin{tabular}{|c|c|c|c|c|c|c|c|c|c|c|c|c|c|c|}
\hline & $\begin{array}{c}\text { Basenji } \\
(\mathrm{n}=1)\end{array}$ & $\begin{array}{c}\text { Chihuahua } \\
(\mathrm{n}=1)\end{array}$ & $\begin{array}{l}\text { Dach. } \\
(n=1)\end{array}$ & $\begin{array}{c}\text { Fox } \\
\text { P. } \\
(n=1)\end{array}$ & $\begin{array}{r}\text { Fox T. } \\
(\mathrm{n}=1)\end{array}$ & $\begin{array}{r}\text { Lhasa } \\
(\mathrm{n}=2)\end{array}$ & $\begin{array}{r}\text { Maltês } \\
(\mathrm{n}=2)\end{array}$ & $\begin{array}{l}\text { P.A. } \\
(n=1)\end{array}$ & $\begin{array}{c}\begin{array}{c}\text { Pinscher } \\
(\mathrm{n}=15)\end{array} \\
\end{array}$ & $\begin{array}{c}\text { Poodle } \\
(\mathrm{n}=38)\end{array}$ & $\begin{array}{l}\text { Schn. } \\
(n=2)\end{array}$ & $\begin{array}{c}\text { Shin- } \\
\text { Tzu } \\
(\mathrm{n}=2) \\
\end{array}$ & $\begin{array}{l}\text { SRD } \\
(n=8)\end{array}$ & $\begin{array}{c}\text { York. } \\
(\mathrm{n}=22)\end{array}$ \\
\hline $\begin{array}{l}\text { grau } \\
1\end{array}$ & & & & & & & & & $12,5 \%$ & $23,9 \%$ & & $50,0 \%$ & $12,5 \%$ & $29,2 \%$ \\
\hline $\begin{array}{l}\text { grau } \\
2\end{array}$ & & $100,0 \%$ & & & & & $50,0 \%$ & & & $10,9 \%$ & & $50,0 \%$ & $12,5 \%$ & \\
\hline $\begin{array}{l}\text { grau } \\
3\end{array}$ & $100,0 \%$ & & & & & & & & $18,8 \%$ & $19,6 \%$ & & & $37,5 \%$ & $20,8 \%$ \\
\hline $\begin{array}{l}\text { grau } \\
4\end{array}$ & & & $100,0 \%$ & $50,0 \%$ & $100,0 \%$ & $100,0 \%$ & $50,0 \%$ & $100,0 \%$ & $43,8 \%$ & $23,9 \%$ & $100,0 \%$ & & $12,5 \%$ & $16,7 \%$ \\
\hline $\begin{array}{l}\text { grau } \\
5\end{array}$ & & & & $50,0 \%$ & & & & & $25,0 \%$ & $21,7 \%$ & & & $25,0 \%$ & $33,3 \%$ \\
\hline
\end{tabular}

Tabela 3 - Comparações entre as raças (Pinscher, Poodle, Yorkshire e Outros) e os graus da doença nos 109 membros estudados, São Paulo - jan.-2000 / dez.-2010

\begin{tabular}{|c|c|c|c|c|c|c|c|c|c|}
\hline & \multicolumn{8}{|c|}{ Raça } & \multirow{3}{*}{$p$-valo } \\
\hline & \multicolumn{2}{|c|}{ Pinscher } & \multicolumn{2}{|c|}{ Poodle } & \multicolumn{2}{|c|}{ Yorkshire } & \multicolumn{2}{|c|}{ Outros } & \\
\hline & $\mathrm{n}$ & $\%$ & $\mathrm{n}$ & $\%$ & $\mathrm{n}$ & $\%$ & $\mathrm{n}$ & $\%$ & \\
\hline grau 1 & 2 & $9,1 \%$ & 11 & $50,0 \%$ & 7 & $31,8 \%$ & 2 & $9,1 \%$ & \\
\hline grau 2 & 0 & $0,0 \%$ & 5 & $55,6 \%$ & 0 & $0 \%$ & 4 & $44,4 \%$ & \\
\hline grau 3 & 3 & $14,3 \%$ & 9 & $42,9 \%$ & 5 & $23,8 \%$ & 4 & $19,0 \%$ & 0,192 \\
\hline grau 4 & 7 & $21,9 \%$ & 11 & $34,4 \%$ & 4 & $12,5 \%$ & 10 & $31,3 \%$ & \\
\hline grau 5 & 4 & $16,0 \%$ & 10 & $40,0 \%$ & 8 & $32,0 \%$ & 3 & $12,0 \%$ & \\
\hline
\end{tabular}




\subsection{SEXO}

A distribuição sexual da necrose asséptica da cabeça femoral está apresentada na tabela 4 .

Ao se comparar os graus da doença com o sexo, nota-se que em todos os graus a maioria eram fêmeas, porém não houve diferença, estatisticamente significante $(p=0,685)$ (Tabela 5).

Tabela 4 - Frequências absolutas (n) e relativas (\%) relacionadas ao sexo dos animais, São Paulo jan.-2000 / dez.-2010

\begin{tabular}{lcc} 
Sexo & $\mathrm{n}$ & $\%$ \\
\hline Macho & 37 & 38,1 \\
Fêmea & 60 & 61,9 \\
Total & 97 & 100,0 \\
\hline
\end{tabular}

Tabela 5 - Distribuição dos graus da doença e o sexo dos animais, São Paulo - jan.-2000 / dez.-2010

\begin{tabular}{lccccc}
\hline & \multicolumn{4}{c}{ Sexo } & \\
\cline { 2 - 5 } & \multicolumn{2}{c}{ Macho } & \multicolumn{2}{c}{ Fêmea } & p-valor \\
\cline { 2 - 5 } & $\mathrm{n}$ & $\%$ & $\mathrm{n}$ & $\%$ & \\
\hline Grau 1 & 10 & $23,8 \%$ & 12 & $17,9 \%$ & \\
Grau 2 & 2 & $4,8 \%$ & 7 & $10,4 \%$ & \\
Grau 3 & 8 & $19,0 \%$ & 13 & $19,4 \%$ & 0,685 \\
Grau 4 & 14 & $33,3 \%$ & 18 & $26,9 \%$ & \\
Grau 5 & 8 & $19,0 \%$ & 17 & $25,4 \%$ & \\
\hline
\end{tabular}

\subsection{MEMBRO ACOMETIDO}

Com relação aos membros acometidos, o membro pélvico direito representa $49,5 \%(n=48)$, o membro pélvico esquerdo $38,1 \%(n=37)$ e animais com ambos os membros acometidos representam $12,4 \%$ dos casos $(n=12)$ (Tabela 6). Após utilizar o estudo Kappa, cada membro foi considerado como informação independente (Tabela 7). Os membros direitos representam 55\% $(n=60)$ e os esquerdos $45 \%$ $(\mathrm{n}=49)$ de um total de 109 membros estudados (Tabela 8). Na comparação do membro acometido com os cinco graus da doença, observou-se uma diferença 
estatisticamente significante $(p=0,028)$, sugerindo que 0 grau 5 está mais presente no membro direito (Tabela 9 ).

Tabela 6 - Frequências absolutas (n) e relativas (\%) relacionadas ao(s) membro(s) acometido(s), São Paulo - jan.-2000 / dez.-2010

\begin{tabular}{lcc} 
Membro acometido & & \\
\hline & $\mathrm{n}$ & $\%$ \\
\hline D & 48 & 49,5 \\
D e E & 12 & 12,4 \\
E & 37 & 38,1 \\
Total & 97 & 100,0 \\
\hline
\end{tabular}

Tabela 7 - Tabela representando o resultado do teste Kappa, utilizado para avaliar a concordância entre os graus da doença nos dois membros acometidos do mesmo animal, São Paulo - jan.-2000 / dez.-2010

\begin{tabular}{|c|c|c|c|c|c|c|c|}
\hline & & & \multicolumn{4}{|c|}{ Classificação (2o membro) } & \multirow[b]{2}{*}{ Total } \\
\hline & & & grau 1 & grau 3 & grau 4 & grau 5 & \\
\hline \multirow{8}{*}{$\begin{array}{l}\text { Classificação } \\
\text { (10 membro) }\end{array}$} & grau 1 & $\mathrm{n}$ & 1 & & & & 1 \\
\hline & & $\%$ & $8,3 \%$ & & & & $8,3 \%$ \\
\hline & grau 3 & $\mathrm{n}$ & & & 1 & 1 & 2 \\
\hline & & $\%$ & & & $8,3 \%$ & $8,3 \%$ & $16,7 \%$ \\
\hline & grau 4 & $\mathrm{n}$ & & & 1 & & 1 \\
\hline & & $\%$ & & & $8,3 \%$ & & $8,3 \%$ \\
\hline & grau 5 & $\mathrm{n}$ & 1 & 2 & 4 & 1 & 8 \\
\hline & & $\%$ & $8,3 \%$ & $16,7 \%$ & $33,3 \%$ & $8,3 \%$ & $66,7 \%$ \\
\hline \multirow[t]{2}{*}{ Total } & & $n$ & 2 & 2 & 6 & 2 & 12 \\
\hline & & $\%$ & $16,7 \%$ & $16,7 \%$ & $50,0 \%$ & $16,7 \%$ & $100,0 \%$ \\
\hline
\end{tabular}

Tabela 8 - Frequências absolutas (n) e relativas (\%) dos membros acometidos, São Paulo - jan.2000 / dez.-2010

Membro acometido

\begin{tabular}{lcc}
\hline & $\mathrm{n}$ & $\%$ \\
\hline D & 60 & 55,0 \\
E & 49 & 45,0 \\
Total & 109 & 100,0 \\
\hline
\end{tabular}


Tabela 9 - Distribuição dos graus da doença e o membro acometido, São Paulo - jan.-2000 / dez.2010

\begin{tabular}{|c|c|c|c|c|c|}
\hline & \multicolumn{4}{|c|}{ Membro acometido } & \multirow{3}{*}{$\mathrm{p}$-valo } \\
\hline & \multicolumn{2}{|c|}{$\mathrm{D}$} & \multicolumn{2}{|c|}{$E$} & \\
\hline & $\mathrm{n}$ & $\%$ & $\mathrm{n}$ & $\%$ & \\
\hline grau 1 & 13 & $21,7 \%$ & 9 & $18,4 \%$ & \\
\hline grau 2 & 3 & $5,0 \%$ & 6 & $12,2 \%$ & \\
\hline grau 3 & 11 & $18,3 \%$ & 10 & $20,4 \%$ & 0,028 \\
\hline grau 4 & 13 & $21,7 \%$ & 19 & $38,8 \%$ & \\
\hline grau 5 & 20 & $33,3 \%$ & 5 & $10,2 \%$ & \\
\hline
\end{tabular}

\subsection{IDADE}

Os dados relacionados às idades (Tabela 10) e a correlação com os graus estão nas Tabelas 11 e 12. Não se observa diferença, estatisticamente significante, entre as diferentes faixas de idade $(p=0,319)$ em relação aos graus da doença.

Tabela 10 - Idade dos animais estudados, São Paulo - jan.-2000 / dez.-2010

\begin{tabular}{lccccc}
\hline & $\mathrm{n}$ & média & desvio padrão & mínimo & máximo \\
\hline Idade (em meses) & 97 & 14,02 & 16,32 & 5 & 108,0 \\
\hline
\end{tabular}

Tabela 11 - Distribuição dos graus da doença e a idade dos animais, São Paulo - jan.-2000 / dez.2010

\begin{tabular}{lccccccc}
\hline & \multicolumn{9}{c}{ Idade } & \\
\cline { 2 - 6 } & \multicolumn{2}{c}{ menos de 1 ano } & \multicolumn{2}{c}{1 ano } & \multicolumn{2}{c}{ mais de 1 ano } & p-valor \\
\cline { 2 - 6 } & $\mathrm{n}$ & $\%$ & $\mathrm{n}$ & $\%$ & $\mathrm{n}$ & $\%$ & \\
\hline grau 1 & 14 & $23,7 \%$ & 5 & $13,2 \%$ & 3 & $25,0 \%$ & \\
grau 2 & 7 & $11,9 \%$ & 2 & $5,3 \%$ & 0 & $0,0 \%$ & \\
grau 3 & 12 & $20,3 \%$ & 7 & $18,4 \%$ & 2 & $16,7 \%$ & 0,319 \\
grau 4 & 12 & $20,3 \%$ & 14 & $36,8 \%$ & 6 & $50,0 \%$ & \\
grau 5 & 14 & $23,7 \%$ & 10 & $26,3 \%$ & 1 & $8,3 \%$ & \\
\hline
\end{tabular}


Tabela 12 - Comparação das variáveis relacionadas à idade (em meses) e os graus da doença, São Paulo - jan.-2000 / dez.-2010

\begin{tabular}{lcccccc}
\hline & \multicolumn{5}{c}{ Classificação } & \multirow{2}{*}{ p-valor } \\
\cline { 2 - 6 } & grau 1 & grau 2 & grau 3 & grau 4 & grau 5 & \\
\hline $\mathrm{n}$ & 22 & 9 & 21 & 32 & 25 & \\
média & 18,6 & 9,6 & 11,5 & 16,3 & 11,2 & \\
desvio padrão & 27,3 & 2,0 & 7,0 & 16,2 & 5,5 & 0,329 \\
mínimo & 5,0 & 7,0 & 0,0 & 5,0 & 6,0 & \\
máximo & 108,0 & 12,0 & 36,0 & 96,0 & 36,0 & \\
\hline
\end{tabular}

\subsection{GRAUS DA DOENÇA}

A frequência de cada grau dos 109 membros estudados estão no gráfico 3.

Gráfico 3 -Frequências absolutas (n) e relativas (\%) relacionadas aos graus da doença nos 109 membros estudados, São Paulo - jan.-2000 / dez.-2010

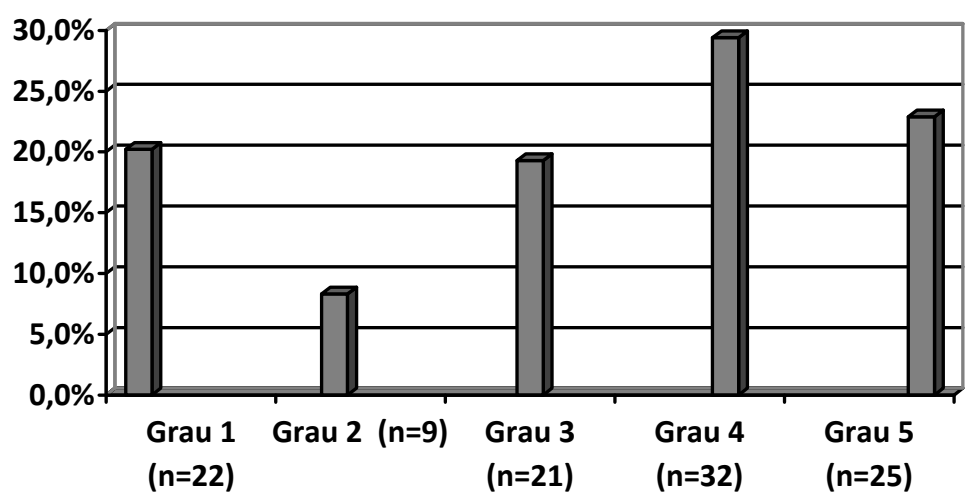

\subsection{EVOLUÇÃO DA DOENÇA}

Dos 97 animais estudados, 15 (15,4\%) apresentaram mais de um exame radiográfico, possibilitando avaliar a evolução da doença (Gráfico 4 e 5). 
Dos 15 animais estudados, 33,3\% permaneceu no mesmo grau da doença; 33,3\% evoluiu (aumentou) um grau; 13,3\% evoluiu (aumentou) três graus e 20\% evoluiu (aumentou) quatro graus do grau inicial (Gráfico 5).

Ao correlacionar a evolução do(s) grau(s) da doença com o tempo observa-se que com menos de 50 dias 57,1\% não mudou o grau da doença e 42,9\% evoluiu apenas um grau. Com o tempo superior a 50 dias, nota-se que 12,5\% não mudou de grau, 25\% evoluiu apenas um grau, 25\% evoluiu três graus e 37,5\% evoluiu quatro graus (Gráfico 6).

Gráfico 4 - Graus de evolução da doença desde a primeira avaliação até a última, São Paulo - jan.$2000 /$ dez.-2010

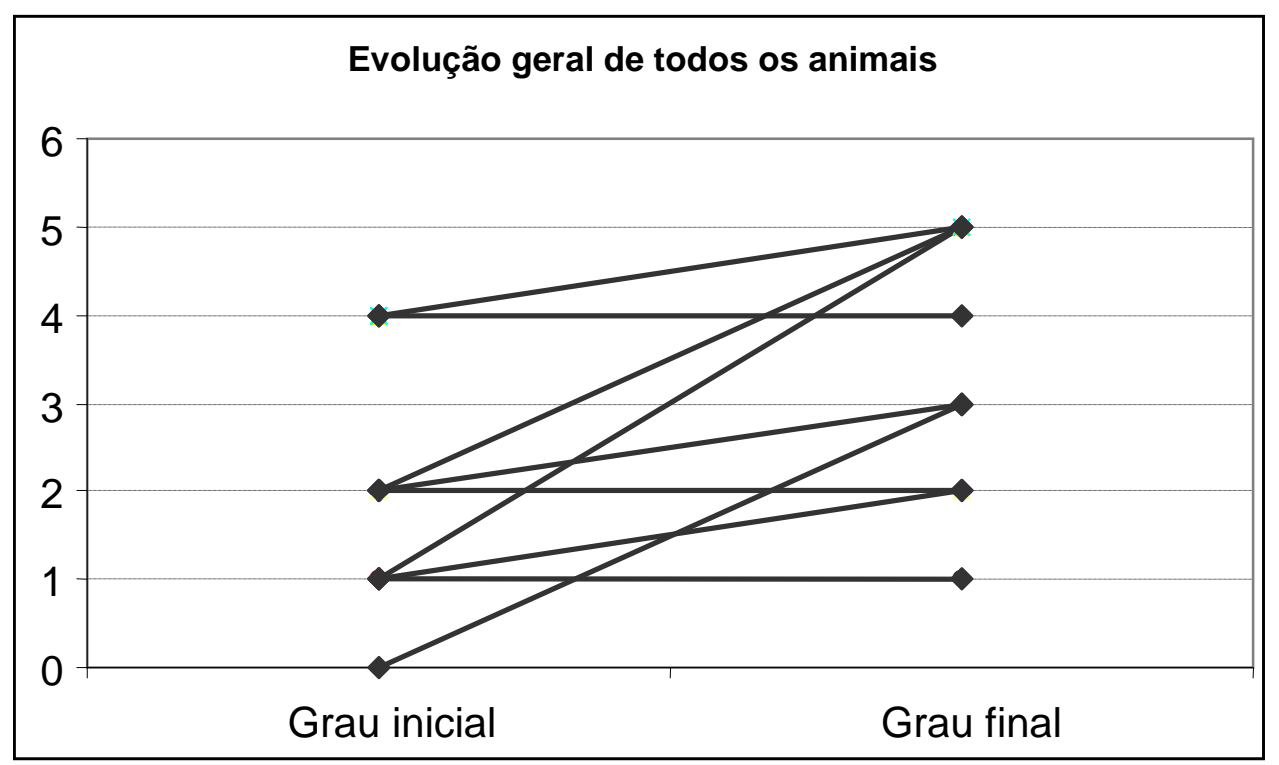


Gráfico 5 - Evolução dos graus da doença, São Paulo - jan.-2000 / dez.-2010

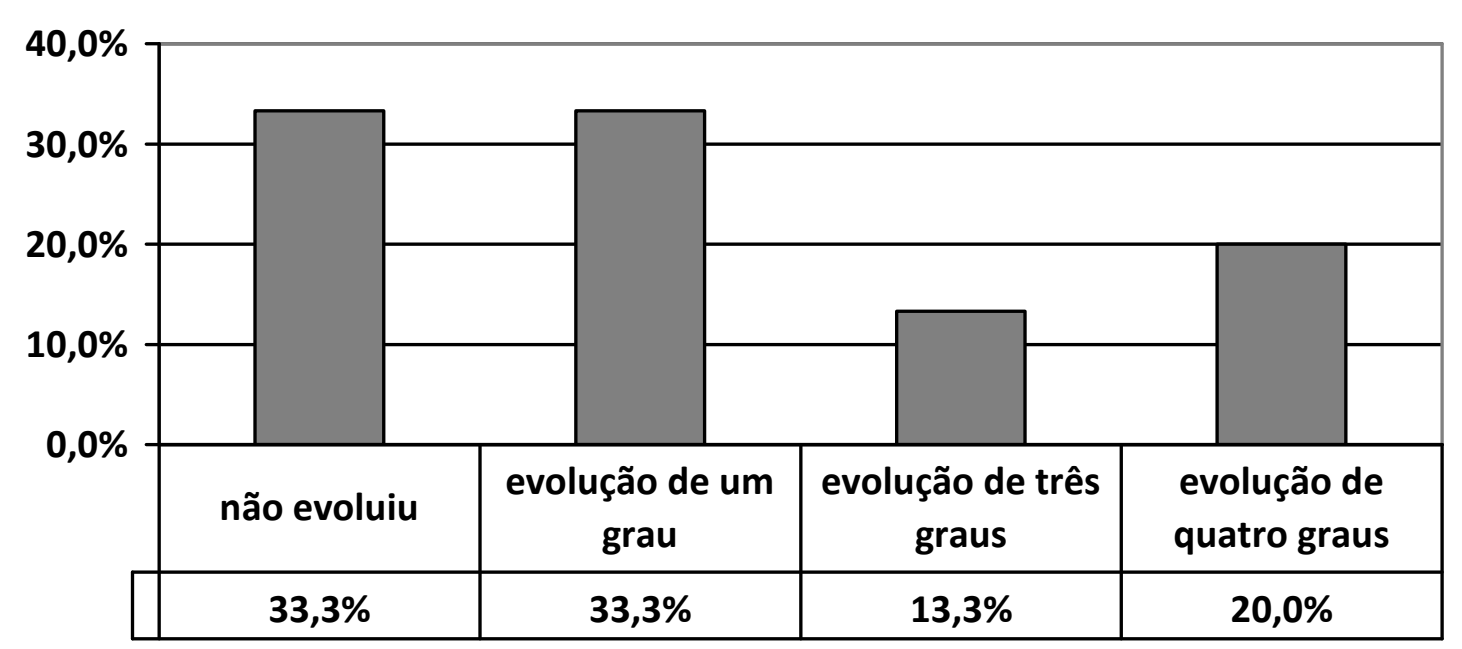

Gráfico 6 - Evolução dos graus da doença classificados em dois grupos (menos de 50 dias e mais de 50 dias de reavaliação), São Paulo - jan.-2000 / dez.-2010

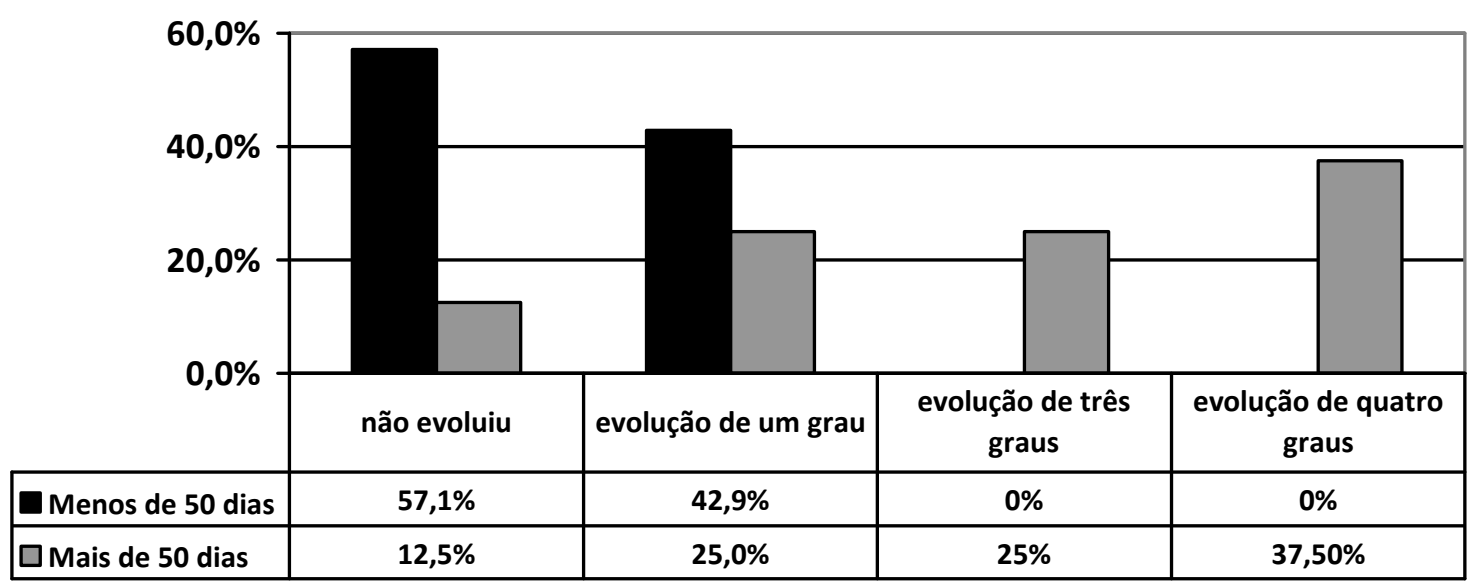




\section{DISCUSSÃO}

\subsection{CASUÍSTICA}

Em um período de dez anos, foi possível estudar a incidência da necrose asséptica da cabeça femoral nos cães atendidos no Hospital Veterinário da Faculdade de Medicina Veterinária da Universidade de São Paulo (FMVZ-USP). Esperava-se que a incidência da doença diminuísse ao longo dos anos. Tal expectativa originou-se devido a uma das possibilidades etiológicas da doença, ser genética e consequentemente, haver hereditariedade. Espera-se que animais com NACF não fossem utilizados como reprodutores, o que talvez pudesse diminuir a incidência da doença. O que não se observou, sugerindo que talvez, nestes casos a seleção não fosse eficiente ou pelos métodos ou pela possibilidade da hereditariedade não ter um papel tão importante quanto imaginado.

Souza et al. (2011) estudou a incidência das afecções dos membros pélvicos e relataram que a NACF representava apenas 1,5\% dos casos. Com o intuito de comparar esses dados com os dados deste trabalho, tentou-se levantar o número total de casos de afecções dos membros pélvicos de cães do Departamento de Cirurgia do HOVET FMVZ-USP. A grande quantidade de casos atendidos (incluindo todos os atendimentos clínico/cirúrgicos, não apenas os casos ortopédicos) e a forma de registro, inviabilizaram a coleta e análise desses dados.

$\mathrm{Na}$ seleção das imagens para o estudo, houve uma grande porcentagem de imagens impressas em filmes radiográficos que não foram encontradas (57\%). Porém, todas as imagens digitalizadas foram encontradas (100\%), começando no meio do ano de 2009 até 2010. Alguns fatores contribuíram para a falta das imagens impressas em filmes. Há a possibilidade dos proprietário terem requerido as imagens. Neste período de 2000 a 2010, o arquivo do setor de Radiologia mudou de lugar, o que pode ter ocasionado o extravio ou perda de algumas imagens. Por se tratar de uma instituição de ensino, o arquivo fica à disposição de todos os alunos, pós-graduandos e professores da Faculdade de Medicina Veterinária da Universidade de São Paulo, e o simples arquivamento em local errado pode 
impossibilitar a localização das mesmas. Atualmente, o arquivo conta com mais de 48.000 exames radiográficos analógicos arquivados. Periodicamente 0 arquivo passava por uma "limpeza", as imagens de pouco valor diagnóstico ou didático eram excluídas do arquivo também.

As imagens digitalizadas ocupam muito menos espaço de armazenamento e aceleram a pesquisa de dados. Mesmo que as imagens sejam requeridas pelo proprietário do animal ou pelo médico veterinário, a instituição continua com as imagens em "backup" para pesquisas futuras. Sem contar a facilidade com que as buscas podem ser realizadas, fornecendo uma ferramenta valiosa para futuros estudos retrospectivos. Atentando-se para o fato de que se as imagens não forem salvas em "backup" e devidamente protegidas, elas podem ser perdidas em sua totalidade, de nada adiantando a digitalização das mesmas.

Nas avaliações das imagens, tanto analógicas quanto digitalizadas, notou-se uma facilidade muito maior nas digitalizadas. As diversas ferramentas (contraste, brilho, zoom, filtros, etc.) que o programa fornece para melhoria ou adaptação da imagem facilitaram muito na avaliação das alterações na cabeça femoral.

\subsection{RAÇA}

Sabendo que a NACF é uma doença autossômica recessiva (PIDDUCK; WEBBON, 1978), ela se expressa apenas em homozigotos, ou seja, a probabilidade da doença acometer os animais de raça pura é maior. E foi o resultado que a pesquisa mostrou, as raças mais acometidas foram Poodles, Yorkshires e Pinschers. Os animais sem raça definida (SRD) representam apenas $8 \%$ do estudo. A pureza da raça dos animais avaliados neste estudo pode ser questionado, pois no momento do cadastro, os dados do paciente são baseadas nas informações do proprietário e/ou na avaliação do fenótipo do animal.

Com base nos dados do presente estudo, notou-se que não há uma predisposição entre as raças acometidas e que independentemente da raça, a grande maioria dos animais são de pequeno porte, comprovando o que Lee (1970) já havia descrito anteriormente. 
No estudo, todas as imagens eram referentes a animais pequenos, com exceção de um que era de grande porte, um cão da raça Pastor Alemão. Este paciente apresentava proliferações ósseas periarticulares exuberantes que alteravam a morfologia da cabeça femoral. Além das alterações proliferativas, havia algumas áreas líticas em permeio que sugeria uma NACF (Figura 08). A idade do animal (07 meses) condiz com a faixa etária predisposta pela doença, bem como as áreas líticas na cabeça femoral que poderiam sugerir NACF. Porém, as proliferações exuberantes são alterações que diferem dos animais de pequeno porte. Tal exame gerou algumas incertezas, portanto foram realizados três controles radiográficos deste animal. A cada controle, as proliferações aumentavam cada vez mais e após o último exame radiográfico, o animal foi submetido à colocefalectomia. Com apenas um animal de grande porte no estudo, não temos como saber se essas alterações radiográficas estão relacionadas à NACF nos animais de grande porte, talvez por se tratar de um animal maior e mais pesado a doença poderia aparecer de outra forma. $\mathrm{Ou}$ as alterações estariam relacionadas à outra doença que não a NACF . São necessários mais estudos sobre esta população de cães para maiores esclarecimentos. E lembrar que estamos estudando uma população de animais e o indivíduo sozinho, às vezes cai no esquecimento por não haver uma diferença estatisticamente significante. 
Figura 08 - Imagem radiográfica de NACF em um cão de porte grande, da raça Pastor Alemão. Observam-se proliferações ósseas periarticulares exuberantes em cabeça, colo e acetábulo direitos, que alteravam a morfologia da cabeça femoral e áreas líticas em permeio à cabeça femoral que poderia sugerir NACF.

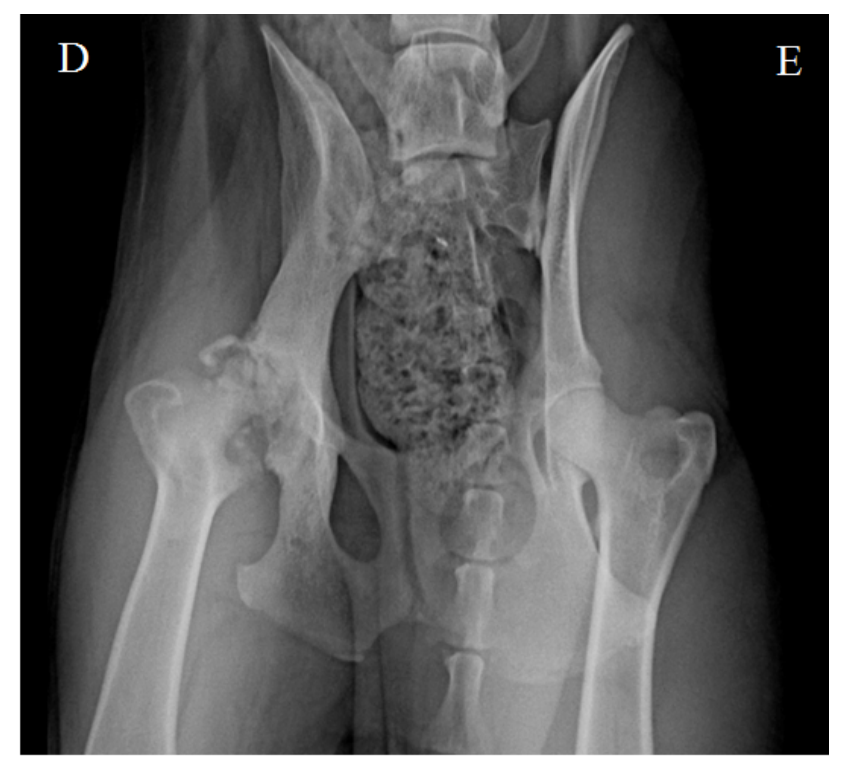

Fonte: Hovet FMVZ-USP, 2010.

\subsection{SEXO}

De todos os animais, 38,1\% eram machos e $61,9 \%$ fêmeas. Além de não haver uma diferença estatisticamente significante entre os sexos, não houve uma diferença significante entre o sexo e os graus da doença também.

\subsection{MEMBRO ACOMETIDO}

Os resultados apresentados ( $88 \%$ unilateral e $12 \%$ bilateral) vão de encontro com os dados relatados por Jonson e Watson (2005), que descrevem uma porcentagem (83-90\%) de pacientes que tinham a doença em um membro só.

Correlacionando os 109 membros com os graus da doença, observou-se uma diferença estatisticamente significante $(p=0,028)(p<0,05)$ em pacientes com grau 5 da doença no membro pélvico direito. Não há relatos em literatura que evidenciem 
esse resultado, mas tal informação poderia ser útil na rotina do clínico/cirurgião veterinário que ao se deparar com um caso em que o animal tem ambos os membros acometidos pela NACF de mesmo grau, poderia começar o tratamento pelo lado direito, já que pelo estudo, o lado direito evolui para o grau cinco com maior frequência.

Por se tratar de um único resultado que teve uma diferença estatisticamente significante e pela ausência deste resultado em literatura, não descartamos a possibilidade de erro, apontado pelo nível de significância (5\%).

Por outro lado, o dado acima sugere a possibilidade de uma lateralidade nos cães, que poderia se manifestar de uma forma mais evidente em animais que tem os dois membros acometidos e uma evolução mais longa da doença. Porém, com base nos casos estudados, esta informação não se confirmou, não havendo diferença estatisticamente significante no lado acometido. Tentamos correlacionar os machos e os membros acometidos para saber se o ato de erguer um dos membros para urinar poderia ter alguma relação com a NACF, mas não houve diferença estatisticamente significante. Tal resultado seria pelo fato da NACF ser uma doença que acomete animais jovens, e esses animais ao urinarem utilizam uma posição de flexão dos membros pélvicos, posição similar ao das cadelas, ou seja, as fêmeas e os machos jovens utilizam uma posição de micção similar, não havendo a elevação de um dos membros pélvicos para urinar. Os machos jovens começam a elevação de um dos membros pélvicos com aproximadamente 5 a 8 meses de idade. (MARTINS; VALLE, 1946) Portanto, neste trabalho em que os animais eram jovens e que não há uma predileção sexual, não foi possível a caracterização de uma lateralidade também.

\subsection{IDADE}

Dos animais estudados, o mais jovem tinha 5 meses de idade e o mais velho, 108 meses, gerando uma média de 14 meses de idade. Apesar de haver animais com mais de um ano de idade, a grande maioria tinham um ano ou menos de um ano de idade (Tabela 11), confirmando a ideia de que a doença acomete animais jovens, como vários autores já tinham descrito. (LEE, 1970; LJUNGGREN, 1967) 
O animal mais velho tinha 108 meses (09 anos) seguido por mais dois cães que tinham 96 meses (08 anos) de idade. Foram os animais com idades mais avançadas e destoantes, porque a média era de 14 meses. Essas três cães eram da raça Poodle, em todos eles o membro acometido era o direito e com relação aos graus, dois eram grau 1 e um era grau 4. Com esses dados, poderíamos sugerir que os Poodles tem uma predisposição mais tardia para a NACF, mas mais uma vez o estudo populacional não nos permite avaliar uma minoria, pois não há uma diferença estatisticamente significante.

\subsection{GRAUS DA DOENÇA}

Independentemente da raça, sexo, idade e membro acometido, o estudo dos graus da doença mostrou que a maioria dos animais apresentavam classificação de grau 4 e a minoria no grau 2. Talvez isso possa ser correlacionado aos sinais clínicos dos pacientes, ou seja, a doença teria seus sinais clínicos mais evidentes e acentuados no grau 4, fase da doença que o animal sente mais dor e claudica mais, ocasionando um aumento no número de casos neste grau. O grau 2 talvez seja a fase da doença que o animal sinta menos dor e claudique menos, diminuindo o número de casos neste grau. Porém, são apenas hipóteses que precisam ser pesquisadas.

\subsection{EVOLUÇÃO DA DOENÇA}

Ao estudar a evolução da doença nos 15 pacientes, observou-se que em nenhum deles houve regressão, permaneceram no mesmo grau no qual a doença fora diagnosticada ou evoluíram para grau(s) superior (es). A maioria (66,6\%) não evoluiu ou evoluiu apenas um grau com menos de 50 dias. Com mais de 50 dias, $33,3 \%$ evoluiu três ou quatro graus. Tais informações indicam que a NACF é uma doença progressiva e de evolução lenta. Portanto, nos casos em que houver a necessidade de realizar um controle radiográfico, recomenda-se que o tempo para 
essa reavaliação seja de pelo menos 50 dias para que as alterações sejam evidentes.

Além de todos os laudos relacionados à NACF em cães possuírem um diagnóstico positivo, apenas $15,4 \%$ realizou controle radiográfico da doença, um índice baixo, demonstrando se tratar de uma doença bem conhecida entre os radiologistas, clínicos e cirurgiões, cuja possibilidade de tratamento, senão o cirúrgico é pouco considerada. Apesar de todos os laudos diagnosticarem a NACF nos pacientes, nenhum deles classificava radiograficamente a doença em graus. A classificação, assim como o emprego de outras modalidades de imagem, poderiam ajudar na conduta e avaliação do caso numa tentativa de explorar outros tratamento senão o cirúrgico.

\subsection{DIAGNÓSTICO}

Diversos métodos de imagem são utilizados para o diagóstico da NACF porém, os demais exames poderiam ser mais utilizados na rotina veterinária, não para diagnosticar a doença mas sim, para trazer informações adicionais pois, quanto maior o número de informações sobre a doença, melhor o planejamento terapêutico.

O ultrassom é um exame de baixo custo, não invasivo e que não requer sedação/tranquilização na maioria das situações. O ultrassom é um método diagnóstico que pode auxiliar em grande escala, por ser realizado com menos sobreposições, graças á diversidade de abordagens (janelas acústicas) que podem ser realizadas, para avaliar as diversas estruturas articulares, principalmente 0 acetábulo e o colo femoral. Uma das etiologias mais aceitas para a NACF é a alteração vascular da cabeça femoral, sendo assim, por se tratar de um exame dinâmico, o ultrassom pode trazer informações de grande valia para estes pacientes, principalmente com o estudo Doppler. Sendo necessários mais estudos para aprimorar e introduzir este exame na rotina de pacientes com NACF. 


\section{CONCLUSÃO}

Esta pesquisa permitiu concluir que:

- As três principais raças acometidas foram Poodles, Yorkshires e Pinschers.

- Não há predisposição sexual.

-A NACF acomete principalmente animais jovens e de pequeno porte.

-Não foi possível observar uma lateralidade nos cães estudados, a não ser no grau 5 que apresentava maior incidência no membro pélvico direito.

-A NACF é uma doença que não regride, ela é progressiva e de evolução lenta.

-A utilização da classificação radiográfica no laudo poderia ajudar o clínico/cirurgião na conduta do caso, quanto ao seu melhor tratamento e talvez nos casos em que o grau da doença fosse baixo, o tratamento conservativo pudesse ser uma opção, evitando procedimentos invasivos.

-Todas as imagens radiográficas digitalizadas foram encontradas, ao contrário das imagens em filme radiográfico. Mostrando a facilidade e rapidez que a digitalização pode trazer para pesquisas futuras. 


\section{REFERÊNCIAS}

BASSET, F. H.; WILSON, J. W.; ALLEN, B. L.; AZUMA, H. Normal vascular anatomy of the head of the femur in puppies with empahasis on the inferior retinacular vessels. Journal of Bone and Joint Surgery, Durhan, v. 51, n. 6, p. 1139-1153, set. 1969.

BOWLUS, R. A.; ARMBRUST, L. J.; BILLER, D. S.; HOSKINSON, J. J.; KUROKI, K.; MOSIER, D. A. Magnetic resonace imaging of the femoral head of normal dogs and dogs with avascular necrosis. Veterinary Radiology \& Ultrasound, Manhattan, v. 49, n. 1, p. 7-12, jul. 2008.

BOWLUS, R. A.; ARMBRUST, L. J.; BILLER, D. S.; HOSKINSON, J. J.; KUROKI, K.; MOSIER, D. A. Magnetic resonance imaging of the femoral head of normal dogs and dogs with avascular necrosis. Veterinary radiology \& ultrasound, Manhattan, v. 49, n. 1, p. 7-12, jul. 2008.

BRENIG, B.; LEEB, T.; JANSEN, S.; KOPP, T. Analysis of blood clotting factor activities in canine Legg-Calvé-Perthes' disease. Journal of Veterinary Internal Medicine, Gottingen, v. 13, p. 570-573, jun. 1999.

BURK, R. L.; ACKERMAN, N. Small animal radiology and ultrasonography. Philadelphia: Saunders, 1996. p. 509-511.

CATTERALL, A. The natural history of Perthes' disease. Journal of Bone and Joint Surgery, Illinois, v. 53, p. 37-53, 1971.

COOK, W. T.; SMITH, M. M. Doença de Perthes. In: SLATER, D. Manual de cirurgia de pequenos animais. 3. ed. New York: Elsevier, 2003. p. 2260-2264.

DOMINGUES, R. C.; DOMINGUES, R. C.; BRANDÃO, L. A.; Imagenologia do quadril. Radiologia Brasileira, São Paulo, v. 34, n. 6, p. 347-367, dec. 2001.

DORIA, A. S.;CUNHA, F. G.; MODENA, M.; MACIEL, R.; MOLNAR, L. J.; LUSO, C.; MOINEDDIN, R.; GUARNIERO, R. Legg-Calve-Perthes disease: multipositional Power Doppler sonography of the proximal femoral vascularity. Pediatric Radiology, São Paulo, v. 38, p. 392-402, feb. 2008. 
DYCE, K. M.; SACK, W. O.; WESING, C. J. G. Membro pélvico dos carnívoros. In: $\overline{456-459 .}$ . Tratado de anatomia veterinária. Rio de Janeiro: Elsevier, 2002. p. 92,

GAMBARDELLA, P. C. Legg-Calvé-Perthes disease in dogs, In: Disease mechanisms in small animal surgery. 2. ed. Philadelphia: Lippincott Williams \& Wilkins, 1993. p. 804-807.

GETTY, R. Osteologia. In: Anatomia dos animais domésticos. 5. ed. Rio de Janeiro: Editora Guanabara Koogan S.A., 1986. p. 19-23.

GIBSON, K. L.; LEWIS, D. D.; PECHMAN, R. D. Use of external coaptation for the treatment of avascular necrosis of the femoral head in a dog. Journal of the American Veterinary Medical Association, Schaumburg, v. 197, n. 2, p. 868-870, mar. 1990.

GLUECK, C. J.; BRANDT, G.; GRUPPO, R., BRIDG, H. Resistance to activated protein $C$ and Legg-Calvé-Perthes disease. Clinical Orthopaedics and Related Research, Cincinnati, v. 338, p. 139-152, may 1997.

GUARNIERO, R.; ANDRUSAITIS, F. R.; BRECH, G. C.; EYHERABIDE, A. P. Classificação e tratamento fisioterapêutico da doença de Legg-Calvé-Perthes: uma revisão. Fisioterapia e Pesquisa, São Paulo, v. 12, n. 2, p. 51-57, set. 2005.

GRESHAKE, R. J.; ACKERMAN, N. Ultrasound evaluation of the coxofemoral joints of the canine neonate. Veterinary Radiology \& Ultrasound, Florida, v. 33, n. 6, p. 99-104, jun. 1992.

HAAGA, J. R.; LANZIERI, C. F.; SARTORIS, D. J.; ZERHOUNI, E. A. O quadril. In: . Tomografia computadorizada e ressonância magnética do corpo

humano. Rio de Janeiro: Guanabara Koogan, 1996. p. 1285-1310.

HICKMAN, J.; SPICKETT, S. G. Avascular necrosis of the femoral head in the dog. Proceedings of the Royal Society of Medicine, Reino Unido, p. 366-399, 1965.

HULSE, D. A.; JOHNSON, A. L. Tratamento da doença articular. In: FOSSUM, T. W. Cirurgia de pequenos animais. Philadelphia: Elsevier, 2002. p. 1057-1058.

HULTH, A.; NORBERG, I.; OLSSON, S. E. Coxa plana in the dog. Journal of Bone and Joint Surgery, Stockholm, v. 44, p. 918-930, jul. 1962. 
JONSON, K. A.; WATSON, A. D. J. Skeletal diseases. In: ETTINGER, S. J.; FELDMAN, E. C.; Textbook of veterinary internal medicine. 6. ed. St Louis: Elsevier/Saunders, 2005. p. 1965-1991.

KEALY, J. K.; MCALLISTER, H. Diagnostic radiology and ultrassonography of the dog and cat. 3. ed. Philadelphia: Saunders, 2000. p. 297.

KRAMER, M.; GERWING, M.; HACH, V.; SCHIMKE, E. Sonography of the musculoskeletal system in dogs and cats. Veterinary Radiology \& ultrasound, Gieben, v. 38, n. 2, p. 139-149, jan. 1997.

LEE, R. A study of radiographic and histological changes occurring in Legg-CalvePerthes disease (LCP) in the dog. Journal of Small Animal Practice, Bearsden, v. 11 , p. 621-638, 1970.

LIU, S. L.; HO, T. C. The role of venous hypertension in the pathogenesis of leggperthes disease. Journal of Bone and Joint Surgery, Illinois, v.73, p. 194-200, 1991.

LJUNGGREN, G. Legg-Perthes disease in the dog. Acta Orthop Scand, Copenhagen, p. 9-76, 1967. Supplementum 95.

MARTINS, T.; VALLE, J. R. A atitude do cão na micção e os hormônios sexuais. Memórias do Instituto Oswaldo Cruz, Instituto Butantã, São Paulo, v. 44, n. 2, p. 343-361, 1946.

OWENS, J. M. Radiographic interpretation for the small animal clinician, Ralston Purina Company, USA, p. 43, 1982.

PIDDUCK, H.; WEBBON, P. M. The genetic control of perthes' disease in toy poodles - a working hypothesis. Journal of Small Animal Practice, London, v. 19, p.729-733, 1978.

RESNICK, D.; KANG, H. S. Pelvis and hip. In: joints. San Diego: Saunders, 1997. p. 473.554. Internal derangement of 
ROBINSON, R. Legg-Calve-Perthes disease in dogs: genetic aetiology. Journal of Small Animal Practice, London, v. 33, p. 275-276, 1992.

SCHEBITZ, H.; WILKENS, H.; Atlas de anatomia do cão e do gato. 5. ed. São Paulo: Manole, 2000. p. 79.

SEER, G.; HUROV, L. Simultaneous bilateral coxo-femoral excision arthroplasty in the dog. Canadian Veterinary Journal, Saskatchewan, v. 9, n. 3, p. 70-73, mar. 1968.

SLATTER, D. Fraturas do fêmur. In: animais. 3. ed. New York: Elsevier, 2003. p. 2059-2062. Manual de cirurgia de pequenos

\author{
(2059-2062.
}

SOUZA, M. M. D.; RAHAL, S. C.; PADOVANI, C. R.; MAMPRIM, M. J.; CAVINI, J. H. Afecções ortopédicas dos membros pélvicos em cães: estudo retrospectivo. Ciência Rural, Santa Maria, v. 41, n. 5, p. 852-857, may 2011.

TROSTEL, C. T.; POOL, R. R.; MCLAUGHLIN, R. M. Canine lameness caused by developmental osthopedic disease: panosteitis, Legg-Calvé-Perthes disease, and hypertrophic osteodystrophy. Compendium, Mississipi, v. 25, n. 4, p. 282-292, april 2003.

TUTT, J. F. D. Tuberculosis of the hip joint in a cairn terrier. Veterinary Record, [S.I.], v. 47, p. 428, 1935.

WALDENSTROM, H. Der obere Tuberculose Collumherd. Ztschr. Orthop Chir., [S.I.], v. 24, p. 487, 1909.

WARREN, D. V.; DINGWALL, J. S. Legg-perthes disease in the dog - a review. Canadian Veterinary Journal, Ontario, v. 13, n. 6, p. 135-137, jun. 1972.

Wenger, D. R.; PANDYA, N.K. A brief history of Legg-Calvé-Perthes disease. Journal of Pediatric Orthopaedics, San Diego, v. 31, n. 2, p. 130-136, set 2011. 
WISNER, E. R.; KONDE, L. J. Diseases of the immature skeleton. In: THRALL, D.E. Textbook of veterinary diagnostic radiology. Philadelphia: Saunders, 2002. p. 149-151. 